WORKING PAPER - NO. 2020-82

\title{
Initial Impacts of the Pandemic on Consumer Behavior: Evidence from Linked Income, Spending, and Savings Data
}

Natalie Cox, Peter Ganong, Pascal Noel, Joseph Vavra, Arlene Wong, Diana Farrell, and Fiona Greig

JULY 2020 


\title{
Initial IMPACTS Of THE PANDEMIC ON CONSUMER BEHAVIOR: EVIDENCE FROM LINKED INCOME, SPENDING, AND SAVINGS DATA $^{*}$
}

\author{
Natalie Cox, Princeton University \\ Peter Ganong, University of Chicago and NBER \\ Pascal Noel, University of Chicago \\ Joseph Vavra, University of Chicago and NBER \\ Arlene Wong, Princeton University and NBER \\ Diana Farrell, JPMorgan Chase Institute \\ Fiona Greig, JPMorgan Chase Institute
}

\begin{abstract}
We use U.S. household-level bank account data to investigate the heterogeneous effects of the pandemic on spending and savings. Households across the income distribution all cut spending from March to early April. Since mid April, spending has rebounded most rapidly for low-income households. We find large increases in liquid asset balances for households throughout the income distribution. However, lower-income households contribute disproportionately to the aggregate increase in balances, relative to their pre-pandemic shares. Taken together, our results suggest that spending declines in the initial months of the recession were primarily caused by direct effects of the pandemic, rather than resulting from labor market disruptions. The sizable growth in liquid assets we observe for low-income households suggests that stimulus and insurance programs during this period likely played an important role in limiting the effects of labor market disruptions on spending.
\end{abstract}

${ }^{*}$ This version: July 21, 2020. This paper was prepared for the Brookings Papers on Economic Activity Conference on June 25, 2020. We thank Therese Bonomo, Peter Robertson, and Tanya Sonthalia for their outstanding analytical contributions to the report. We thank Jonathan Parker, Jan Eberly, and Erik Hurst for helpful discussions. We are additionally grateful to Samantha Anderson, Maxwell Liebeskind, Robert McDowall, Shantanu Banerjee, Melissa Obrien, Erica Deadman, Sruthi Rao, Anna Garnitz, Jesse Edgerton, Michael Feroli, Daniel Silver, Joseph Lupton, Chris Knouss, Preeti Vaidya, and other members of the JP Morgan Chase Institute for their support, contributions, and insights. 


\section{Introduction}

The Covid-19 pandemic led to a large and immediate decline in U.S. aggregate spending and an increase in aggregate private savings. In this paper, we use anonymized bank account information on millions of Chase customers to measure the microeconomic dynamics underlying these aggregate patterns. Specifically, we use our household level account data to explore how spending and savings over the initial months of the pandemic vary with household-specific demographic characteristics, such as pre-pandemic income and industry of employment.

Figure 1: Aggregate Consumption and Savings

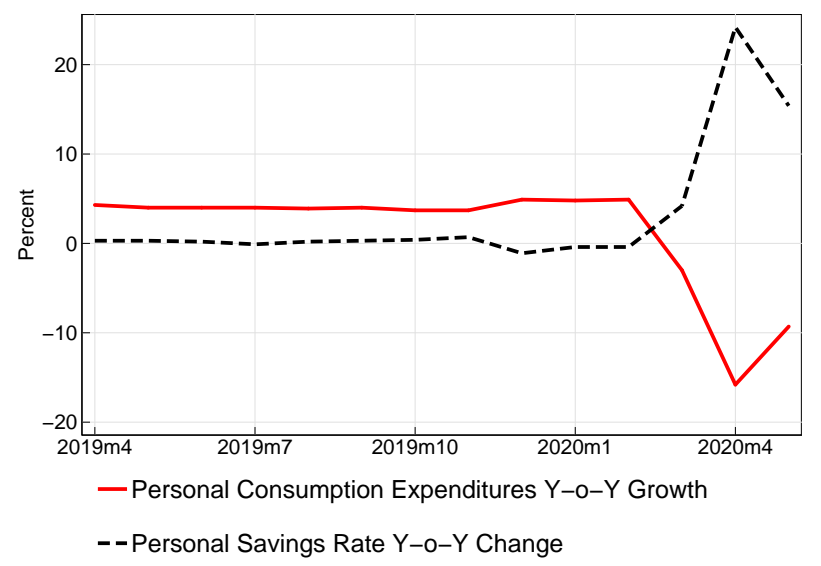

Figure shows the year-over-year growth of Personal Consumption Expenditures and change in the Personal Savings rate, calculated from monthly Bureau of Economic Analysis data.

Measuring and understanding the link between income, spending, and savings is useful for understanding the causes and dynamics of this recession. For instance, the relationship between individual income, spending and savings can shed light on the role of supply factors (such as shutdowns and reducing activities with high infection risk) versus demand factors (such as Keynesian spill-overs across sectors as unemployed workers reduce spending). Understanding these factors can be informative about the effectiveness of different stimulus policies for targeting different households and businesses. Many data sets have already been used to study the dynamics of geographic level spending during the pandemic, but aggregated relationships may or may not be identical to those at the individual household level at which economic behavior is ultimately determined. ${ }^{1}$ Our paper provides an initial step in analyzing these household-level dynamics. ${ }^{2}$

Focusing first on aggregate results, we find that overall spending fell over $35 \%$ in the second

\footnotetext{
${ }^{1}$ See e.g. Chetty et al. (2020).

${ }^{2}$ To be clear, our current analysis does not run regressions at the household level, but it does crucially rely on individual household data to define groups and outcomes of interest. We also focus for now on sorting households by pre-pandemic characteristics like income level, rather than by changes during the pandemic.
} 
half of March. In April, spending began to increase from its nadir, but it remained substantially depressed through the end of our sample on May 30. Declines in non-essential spending accounted for most of the declines in spending. ${ }^{3}$ Amongst non-essential categories, declines were particularly large for restaurants, hotel accommodations, and clothing and department stores. Amongst essential categories, declines were most dramatic for healthcare, ground transportation and fuel. Reassuringly, these patterns are similar to those found using other aggregate sources of spending data. ${ }^{4}$, EarnestResearch (2020), Baker et al. (2020), Chetty et al. (accessed on 06/15/2020), Facteus (accessed on 06/15/2020) and Karger and Rajan (2020). However, this also implies that these results do not rely on the unique features of our micro data, so they are not the main contribution of our paper.

We next turn to results which do rely on our micro data linking household-level observables on income, spending and savings. First, we find that during the initial stages of the pandemic in March, there are extremely large declines in spending for all quartiles of the pre-pandemic income distribution. ${ }^{5}$ Spending by the top quartile of the income distribution falls by modestly more than any other quartile (in percentage terms). However, this difference is small relative to the broad decline in spending by all income groups. Beginning in mid April when aggregate spending begins to recover, substantial differences by income emerge: spending recovers much more rapidly for low-income households than for high-income households so that large differences arise by the end of May. We show that these relationships between income and spending over the pandemic hold both in general, as well as within narrow geographic areas like zip codes. ${ }^{6}$

Second, we explore differences in spending by individual's industry of employment. This variation is interesting because industries vary substantially in both their exposure to labor market disruptions and in average income levels. Exploiting joint variation in industry of employment and household income is thus helpful for better understanding the source of heterogeneity in spending patterns. We find that spending cuts are pervasive, with declines for workers in all industries of employment. Consistent with the patterns we find by income, workers in industries with low average pay initially cut spending slightly less and then have spending which recover more rapidly. For example, grocery store workers have the smallest declines in spending and the most rapid rebound, while white collar professional workers' spending is recovering more

\footnotetext{
${ }^{3}$ We define these categories precisely later, but loosely speaking non-essential stores are those which are subject to government restrictions as a result of the pandemic.

${ }^{4}$ See for example

${ }^{5}$ As we discuss more in Section I, since our data arises from bank account information, we under sample the very lowest income households, but the sample is otherwise broadly representative.

${ }^{6} \mathrm{High}$ and low income people live in different locations, which might have different exposure to the pandemic. Using within zip code variation shows that income-spend relationships are not driven by confounding effects of physical location.
} 
slowly. We then further split workers within given industries of employment by their individual pre-pandemic income levels. We find that income appears to matter more for spending than industry of employment. For example, low-income workers in all industries have rapid increases in spending in mid April, while these increases are muted for high-income workers.

Finally, we turn to evidence on the distribution of household savings over the pandemic to provide further insight into the effects of changing income and spending on household liquidity. To the best of our knowledge, we are the first paper to explore these distributional effects. Aggregate savings have increased substantially over the last two months. Information on the underlying distribution of increases is useful for understanding the sources and consequences of this increase. There are several forces during the pandemic that likely affected aggregate savings rates: 1) As discussed above, spending has fallen. This decline is most dramatic at the top of the income distribution, which will tend to boost savings for these households. 2) Massive increases in unemployment have reduced labor income, and these effects are especially concentrated on low-income workers. This will tend to reduce savings for low-income households. 3) Stimulus and social insurance programs like Economic Impact Payments (EIP) and expanded unemployment insurance (UI) provide transfers which represent a larger share of income for low than high-income households. This will tend to increase liquidity and savings by low-income households. 4) Delayed tax filing dates may increase short-term savings if those who owe money delay filing more often than those who are owed refunds.

Consistent with aggregate savings data, we find a large initial increase in savings during the pandemic. By the end of May 2020, average liquid balances are 36\% higher than at the same point in 2019. While increases in liquid balances are pervasive throughout the income distribution, we find that lower-income households contribute disproportionately to the aggregate increase in balances, relative to their initial pre-pandemic shares. That is, liquid balances at the end of May are slightly more equally distributed over the income distribution than liquid balances in February. However, in dollar terms, high-income households contribute most to the aggregate increase in savings.

Taken together, our results suggest several conclusions. First, labor market disruptions were unlikely to be a primary factor driving initial spending declines during the recession. Overall declines in spending were much larger than what could be explained by the rise in unemployment in this recession, given historical relationships. Furthermore, spending actually declines by less for households with greater exposure to labor market disruptions. This does not mean that labor market disruptions have no effects on spending or that demand spillovers are unimportant, but it does suggest that at least in these initial months of the recession, the direct effects of the pandemic are the primary factor driving spending. 
Second, the composition of typical spending is important for understanding spending declines. Aggregate spending declines by more in non-essential sectors which are more exposed to shutdowns and health risk. Furthermore, spending declines more for high-income households, who tend to consume more of these non-essential goods in normal times.

Third, various stimulus and social insurance programs like EIP and expanded UI likely played a sizable role in helping to stabilize spending and liquid balances, especially for low-income households. Since fiscal stimulus was ramped up at the same time that many states began to reopen, it is difficult to disentangle general "re-opening" effects from effects of this fiscal stimulus by looking just at aggregate spending. However, stimulus checks and expanded UI benefits represent a larger share of monthly income for low-income workers than for high-income workers, and would thus naturally explain the more rapid recovery in spending we observe for low-income workers. Finally, expanded transfers could also explain the disproportionate increase in savings that we observe for lower-income households. It is important to note that many of these transfer programs are likely temporary - the EIP payments are a one-off stimulus, while the expanded component of UI benefits is slated to end in late July 2020. Households may be less likely to immediately consume, and more likely to save, these payments because they are non-permanent.

It is important to emphasize that our evidence for now focuses on time-series patterns for relatively aggregated household groups, and so we do not provide any causal evidence on the strength of any particular channels driving spending decisions. Thus, our evidence is suggestive rather than conclusive on this front. The early patterns we find in this paper may also change as the pandemic progresses and new policy decisions are made. Future work exploring even more detailed household level results as this recession progresses will hopefully shed further light on the economic consequences of this pandemic and associated policy responses.

\section{Data Description}

Our analysis of spending and checking account balances is based on the universe of transactions from Chase checking accounts, debit cards, and credit cards through May 30, 2020. Our main measure of total spending includes all debit and credit card purchases as well as cash withdrawals. In robustness checks in the Appendix we show that our conclusions are similar if we add paper checks to our measure of total spending. ${ }^{7}$ While we observe credit, debit, cash, and check transactions, we are still working to process electronic checking account transactions such as ACH payments and so this type of spending is not included in our analysis. For all checking accounts,

\footnotetext{
${ }^{7}$ We do not include paper checks in our main analysis for two reasons. First, we do not know whether the checks reflect spending, debt payments, or transfers. Second, due to delays in depositing and processing checks, there is a lag between when the check was used and when it appears as a withdrawal in the bank account. Hence, it is hard to interpret the patterns of paper check outflows at the high frequency we use in this analysis.
} 


\section{Table 1: Income Distribution and Credit Cards Spending}

\begin{tabular}{|c|c|c|c|c|}
\hline & \multicolumn{4}{|c|}{ Income Quartiles } \\
\hline & Quartile cut-offs & Mean income & $\begin{array}{c}\% \text { Sample with Credit } \\
\text { Card }\end{array}$ & $\begin{array}{c}\text { Avg. Weekly Credit Card } \\
\text { Spend }\end{array}$ \\
\hline Quartile 1 & $\$ 12,000-\$ 27,707$ & $\$ 20,948$ & $30 \%$ & $\$ 205$ \\
\hline Quartile 2 & $\$ 27,707-\$ 41,255$ & $\$ 34,185$ & $36 \%$ & $\$ 228$ \\
\hline Quartile 3 & $\$ 41.255-\$ 63,462$ & $\$ 50,927$ & $46 \%$ & $\$ 329$ \\
\hline Quartile 4 & $\$ 63,462+$ & $\$ 108,914$ & $57 \%$ & $\$ 639$ \\
\hline $\mathrm{N}$ & $5,014,672$ & & & \\
\hline
\end{tabular}

*The last two columns provide the percentage and average spending of any individuals with a Chase credit card.

we also observe checking account balances.

We impose income and activity screens in order to focus on a sample of individuals who primarily use their Chase account to manage their finances. Specifically, we filter on those who have a non-business account, had at least five checking account transactions and at least three card transactions in every month between January 2018 and March 2020, and had at least \$12,000 in labor income in both 2018 and 2019. ${ }^{8}$ This leaves us with a sample of just over five million individuals.

We measure labor income using information on payroll direct deposits. We further measure industry of employment based on the payer associated with direct deposits in February 2020. However, there is an important caveat that we can match the payer associated with payroll income to an identified payer for only $24 \%$ of households, and most of these payers tend to be large employers. Finally, it is important to note that while we observe labor income through February, 2020, we are still working to process and interpret data on labor income and government transfers during the pandemic. As a result, data on income changes during the pandemic are not available for our current analysis. For this reason, we report various results based on pre-pandemic income, but do not yet have results on how spending has responded to individual income changes.

Given that our sample is drawn from account holders at a single financial institution, we use income data from the CPS to measure how representative it is of the US population. Table 1 reports quartiles of the labor income distribution for our sample. Figure A.12 plots the average labor income by quartile for the Chase sample compared to average labor income for the CPS population (adjusted for income and payroll taxes since the Chase measure is post-tax). This figure suggests that our sample is broadly representative, although it somewhat overstates income at the lowest end of the distribution and slightly understates income at the highest end of the distribution. The overstatement at the lowest end of the distribution is due to two factors. First,

\footnotetext{
${ }^{8}$ We have explored different thresholds on transactions and results are similar.
} 
reliable measurement requires us to impose a minimum threshold of $\$ 12,000$ in labor income. ${ }^{9}$ In the CPS, 7.7\% of households have labor income below this cutoff. They would be excluded from our analysis. ${ }^{10}$ Second, every household in our data set has a bank account. Therefore, we do not include unbanked households, who are disproportionately low-income. The FDIC reports that $6.5 \%$ of U.S. households did not have a bank account in $2017 .{ }^{11}$ A final caveat for our analysis is that we report average outcomes in terms of spending and liquid balances by income quartile. However, there may be heterogeneity within quartiles. For example, not all households were eligible for EIP payments and some unemployed households faced long delays in receiving UI payments. For all these reasons, our findings that average spending and average balances are relatively higher for low-income households should not be interpreted to mean that all lowincome households are doing relatively well during the pandemic. There is compelling evidence that this is not the case (Bitler, Hoynes, and Schanzenbach, (2020).

Our data are unique in their size, sample coverage, and in their individual-level view of income, spending, and balances. Other data sources used to research the consumer response to COVID-19 tend to be aggregated over region, store, or time (e.g. Earnest, Womply, or Affinity), which limits the analysis of household balance sheet dynamics. By observing covariates at the individual level, like geography and industry of employment, we can also directly control for confounding factors that might be correlated with income and changes in spending. For example, our data can be used to look at how spending varies with income within narrow geographic areas like zip codes, and thus help control for the fact that high-income locations differ from lowincome locations along a number of dimensions. Our data also allows us to look at how spending changes by income groups within industry of employment.

Our sample, which captures households across the income distribution, complements the work done using Facteus data (e.g. Karger and Rajan (2020), Alexander and Karger (2020)) and proprietary Fintech data (Baker et al. (2020)) which is primarily focused on low-income households. Finally, the size of the Chase customer base allows for additional precision when calculating statistics of interest as well as for substantially more disaggregated data cuts, relative to data sets with smaller sample sizes. Our data is closest in structure to that in Andersen et al. (2020), which uses similar bank account data from a Scandinavian bank. The most important distinction is that our data covers U.S. households, and thus a dramatically different institutional environment with different social safety nets and government responses to the pandemic.

\footnotetext{
${ }^{9}$ We require at least $\$ 12,000$ in labor income since it is difficult to distinguish truly low income households from mis-measured higher income households without reliably captured direct deposits.

${ }^{10}$ After conditioning on households with labor income above $\$ 12,000$ in the CPS, mean and median income in the bottom quartile of our sample is very similar to mean and median income in the bottom quartile of the CPS.

${ }^{11}$ See 2017 FDIC National Survey of Unbanked and Underbanked Households, Executive Summary.
} 


\section{Household Spending}

\section{II.A. Overall Change In Spending}

We begin by measuring the change in total spending. Appendix A.1 provides changes in spending for each of the components of total spending (credit card, debit card, and cash), as well as paper checks. Panel (a) of Figure 2 plots the 2020 to 2019 year-over-year percentage change in weekly spending. Panel (b) shows the average dollar amount of spending in 2020 and 2019. Changes in spending follow a distinctive pattern: spending is stable through the beginning of March, then declines precipitously by over 35 percent relative to 2019 from the second through fourth week of March. The size of the spending drop is largely consistent with other estimates from similar data sources during the same time frame. ${ }^{12}$ These declines are somewhat larger than the aggregate spending declines in Figure 1, but this is not particularly surprising. Personal consumption expenditures includes substantial spending on components like housing services, which likely had little to no decline. Spending showed signs of recovery in May, but remains roughly 15 percent below pre-pandemic levels as at the end of May.

Figure 2: Average Spending Changes

(a) Percent Change

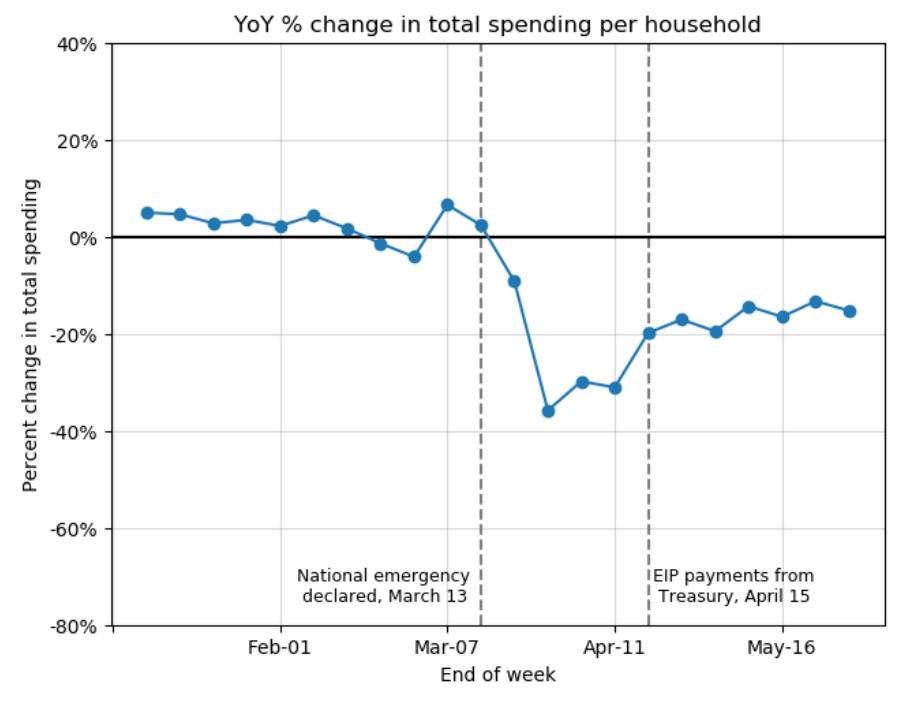

(b) Levels

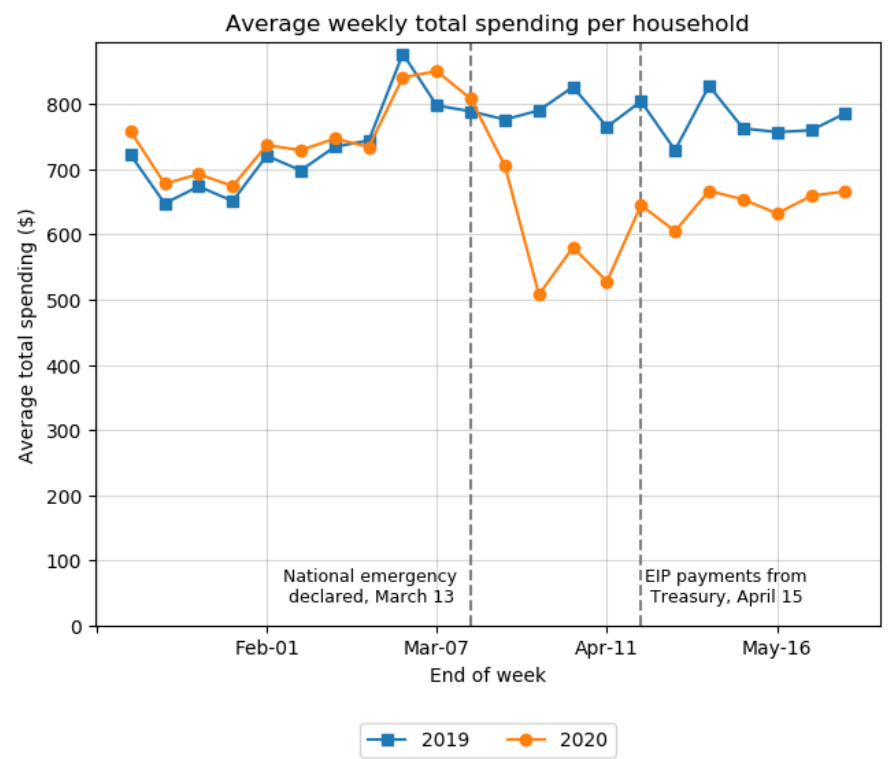

The left panel plots the year-over-year percentage change in weekly spending. The right panel plots the dollar change in weekly spending. Vertical lines show the date when the national emergency was declared and the date on which a majority of EIP payments arrive.

The timing of the initial spending drop mirrors the spread of the virus and staggered national

\footnotetext{
${ }^{12}$ See for example, Baker et al. (2020), Chetty et al. (accessed on 06/15/2020), and Facteus (accessed on 06/15/2020).
} 
implementation of government social distancing orders. A national emergency was declared on March 13, 2020. Over the following three weeks, the number of states with stay-at-home orders increased from zero to forty-five. The prevalence of COVID-19 also increased dramatically over the course of March.

At the same time, the drop in spending also closely tracks the pattern of initial job losses. Unemployment Insurance (UI) claims began spiking in the third week of March, with more than 20 million UI claims filed by April 11. Conversely, spending begins to recover in the weeks after April 15 when a majority of EIP payments arrive and as many of the unemployed workers who file claims in March and early April begin to receive benefits. This raises a question of how much of the drop in spending is due to the pandemic itself, the social distancing policies, or income losses.

It is useful to calibrate the size of the spending drop relative to what we have observed among those who lose a job involuntarily during normal times. Ganong and Noel (2019) measure the spending drop around job loss among UI recipients, and observe an initial spending drop of roughly $6 \%$. In other words, the spending drop in March 2020 is roughly six times larger than the average household spending drop in the first month of unemployment for UI recipients in normal times. This puts into perspective how dramatic the spending drop is and suggests that the pandemic and policies aimed at preventing its spread are contributing substantially to the drop in spending.

\section{II.B. Change In Household Spending By Categories}

While Figure 2 shows a sharp drop in aggregate spending over March and April, there is reason to think that specific spending categories would be differentially impacted. Many non-essential businesses, like bars and salons, were closed by state and local governments. Similarly, stay-athome orders limited the ability of individuals to travel. Beyond the mechanical effect of social distancing regulations, individuals may also have independently curtailed spend in certain categories to avoid risk of infection or as a response to income loss.

While we do not have information on debit card or cash spending by categories, we do have detailed category splits for credit card spending. We begin by disaggregating total credit card spending into essential and non-essential categories, as commonly defined in state "stay-at-home" orders. Figure 3, panels a and b, show a dramatic difference in the path of essential and nonessential spending. Essential spending spiked in early March as households stockpiled goods like groceries. It then fell substantially before eventually stabilizing at a year-over-year decline of around 15 percent. ${ }^{13}$ In contrast, spending on non-essential categories fell sharply throughout

\footnotetext{
${ }^{13}$ The downward spike in year-over-year essential spending in the week ending April 18, 2020 likely arises because
} 
March, bottoming at a decline of just over 50 percent, and then began to slowly recover through late April and May.

Figure 3: Credit Card Spending on "Essential" and "Non-Essential" Categories

(a) Percent Change

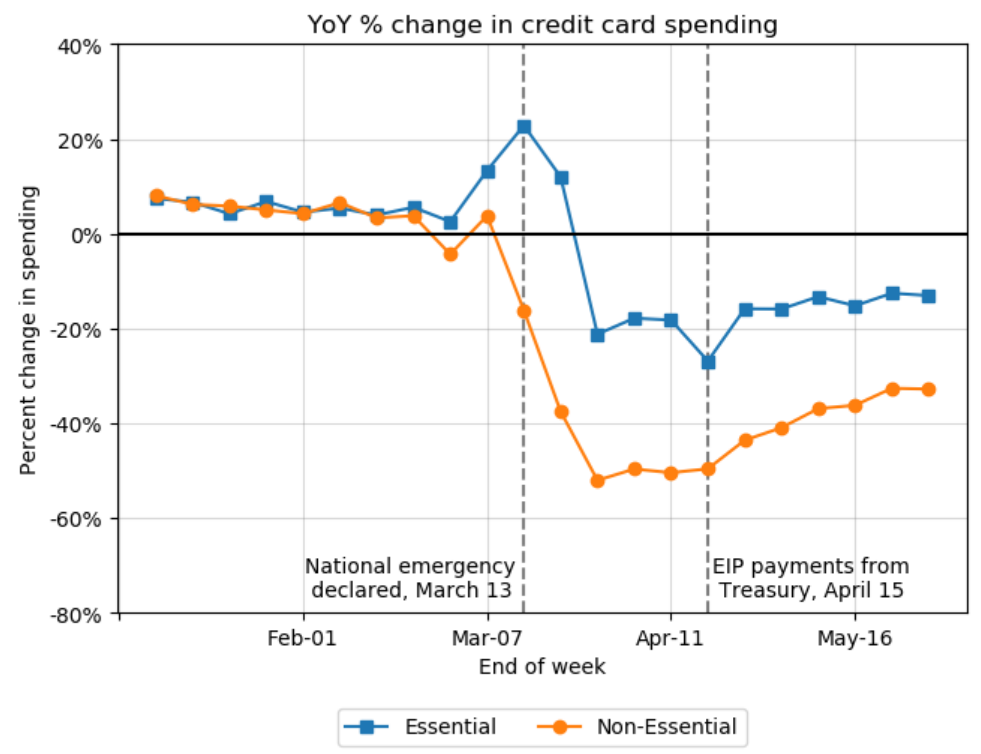

(b) Levels

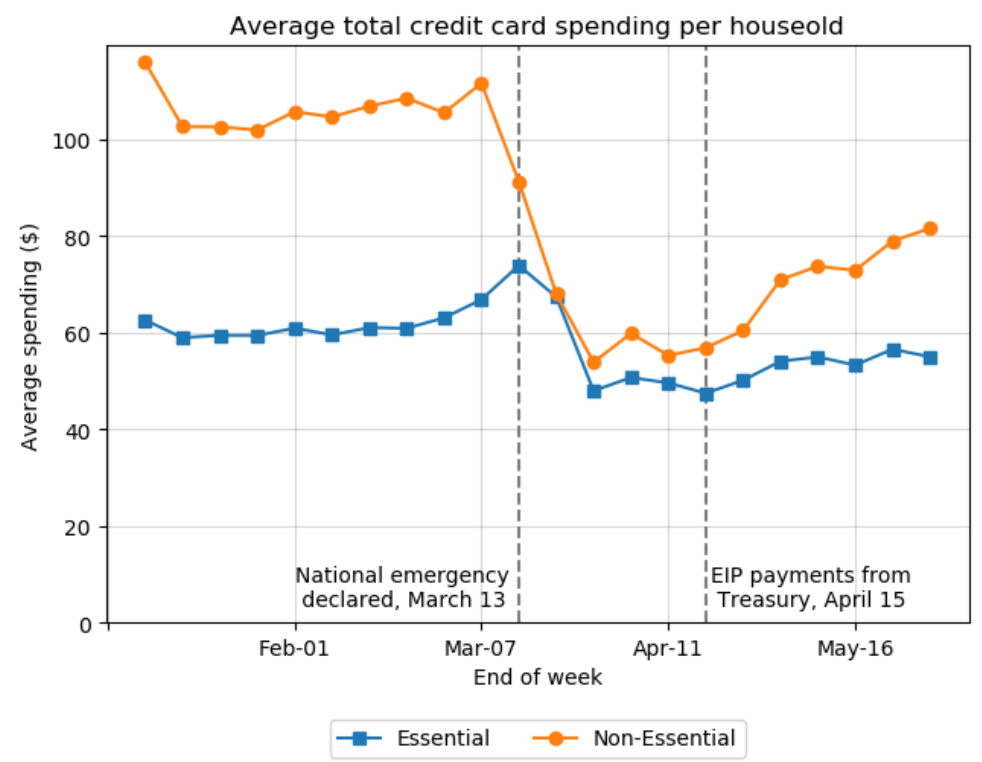

We use state social distancing orders that restricted non-essential goods and services to categorize spend. "Essential" categories include fuel, transit, cash, drug stores, discount stores, auto repair, groceries, telecom, utilities, insurance, and healthcare. "Non-essential" includes department stores, other retail, restaurants, entertainment, retail durables, home improvement, professional and personal services, and miscellaneous. Although flights, hotels, and rental cars are sometimes categorized as "essential" and not technically closed, we include them in the "non-essential" group because they are affected by stay-at-home restrictions on non-essential travel.

Given the fact that households were ordered to stay at home except to make essential trips in most states, one might ask why households were still spending roughly $\$ 50$ a week on nonessential categories in April. First, there was variation in both the degree of closures and in what was deemed non-essential across locations. Second, our spending categories do not map perfectly to each specific non-essential category. Third, households may be able to switch some non-essential services from in-person to remote; for example from movie theater entertainment to online streaming or from in-restaurant dining to take-out.

We also quantify how much each category contributed to the aggregate drop in credit card spend. Table 2 shows what share of aggregate spending went towards essential and non-essential categories before and during the pandemic. Multiplying the pre-pandemic shares by their relative percentage drops, we find that non-essential spending accounted for $84 \%$ of the aggregate decline, and essential spending accounted for $16 \%$.

of the timing of Easter, which occurred during this week in 2020 but during the previous week in 2019. Many grocery stores are closed on Easter, which may explain a dip during this week in 2020 relative to the same week in 2019, which 
Table 2: Credit Card Spending Changes for "Essential" and "Non-Essential" Categories

\begin{tabular}{|c|c|c|c|c|}
\hline & \multicolumn{2}{|c|}{ Essential } & \multicolumn{2}{c|}{ Non-Essential } \\
\hline & $\begin{array}{c}\text { Share of } \\
\text { spending }\end{array}$ & $\begin{array}{c}\text { Year-over-year } \\
\text { percent change }\end{array}$ & $\begin{array}{c}\text { Share of } \\
\text { spending }\end{array}$ & $\begin{array}{c}\text { Year-over-year } \\
\text { percent change }\end{array}$ \\
\hline Apr-19 & $35 \%$ & & $65 \%$ & \\
\hline Apr-20 & $46 \%$ & $-18 \%$ & $54 \%$ & $-49 \%$ \\
\hline \hline $\begin{array}{c}\text { Contribution to } \\
\text { Aggregate Drop in } \\
\text { Spend* }\end{array}$ & $16 \%$ & & $84 \%$ & \\
\hline
\end{tabular}

* Percent contribution to aggregate drop in spend is calculate as: $(\% \text { Drop in Category A })^{*}($ Baseline Share of Category A) /(\% Drop in Aggregate).

To further illustrate the divergence in spending patterns across categories, we split essential and non-essential spending into more disaggregated categories in Figure 4. Total essential spending spiked by roughly $20 \%$ in early March before dropping by $20 \%$ by end-March. However, there are a wide range of spending responses among goods and services deemed essential. In the first few weeks of March there was a temporary surge in spending on groceries, discount stores, and pharmacies. Spending at grocery stores, which contributes the largest share of total essential spending, remained elevated through the end of our sample, aside from a brief decline in the week including Easter, when many grocery stores are closed. In contrast, spending fell in several other essential categories like "hospital", "other healthcare", "transit and ground transportation", and "fuel". Total dollar declines in these categories exceed the dollar increases in grocery spending, so that overall essential spending declines. Focusing on non-essential spending, declines are strongest in restaurants, hotel accommodations, and clothing and department stores. Overall, these results largely mirror those computed in other aggregate data sets and provide reassurance that our data is consistent with external evidence.

\section{II.C. Heterogeneity In Spending Changes By Income SPENDING CHANGES OVER THE INCOME DISTRIBUTION}

We next explore whether spending reductions (both in aggregate and by category) vary with prepandemic income. We stratify our sample into income quartiles based on total labor inflows in 2019. ${ }^{14}$ For context, those in the bottom quartile make less than $\$ 28,000$ in take-home labor income per year, while those in the top quartile earn more than $\$ 63,000$. As discussed in Section I, our bottom quartile misses unbanked households and the $8 \%$ of U.S. households with labor income

did not include the Easter closures.

${ }^{14}$ In future work, we plan to explore also the relationship to income changes during the pandemic. 


\section{Figure 4: Credit card spending growth across spending categories}
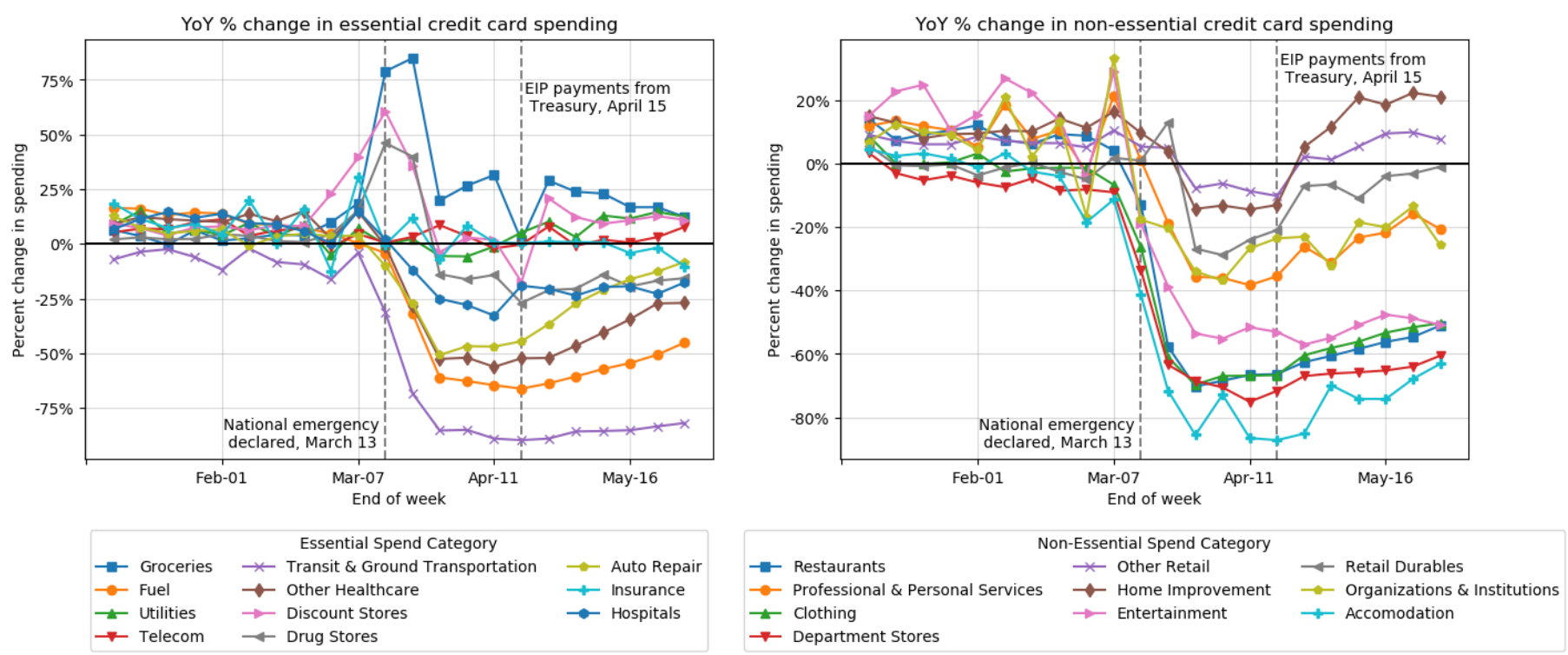

below $\$ 12,000$, since we cannot reliably measure their income.

Figure 5 plots the year-over-year change in spending for each quartile, both in percentage and dollar terms. The top income quartile reduces spending by about 39 percent, or $\$ 400$, by the fourth week of March, while the bottom quartile reduces spend by 32 percent, or $\$ 100$. The difference in the spending drop between income quartiles is starker in dollar terms than percentages, since high-income households have a higher baseline level of spending. However, divergence in spending over the income distribution starting in the second half of April is more striking. By the end of April, the decline in spending partially recovers, with the recovery most pronounced for the lowest income quartiles. The recovery in spending for the lowest income quartiles occurs in the same week when many stimulus payments are made in mid April. The timing of the divergence in spending by income suggests that stimulus payments may have played an important role in restoring the ability of low-income households to maintain spending during the pandemic.

Appendix A.2 provides the spending changes over the income distribution by form of payment (debit, credit, cash and check). We observe similar patterns of spend changes across all forms of payments.

Table A.1 reports the cumulative change in spending by income quartile in 2020 relative to 2019 for the 11 "pandemic" weeks in our dataset between March 15 and May 30. The highest income quartile contributes disproportionately to the change in spending, accounting for $37 \%$ of initial spending and $50 \%$ of the spending decline. As a result, the share of spending for the highest income quartile declined.

While the results so far show that households with higher income cut spending by more and 
Figure 5: Spending by income quartiles

(a) Percent Change

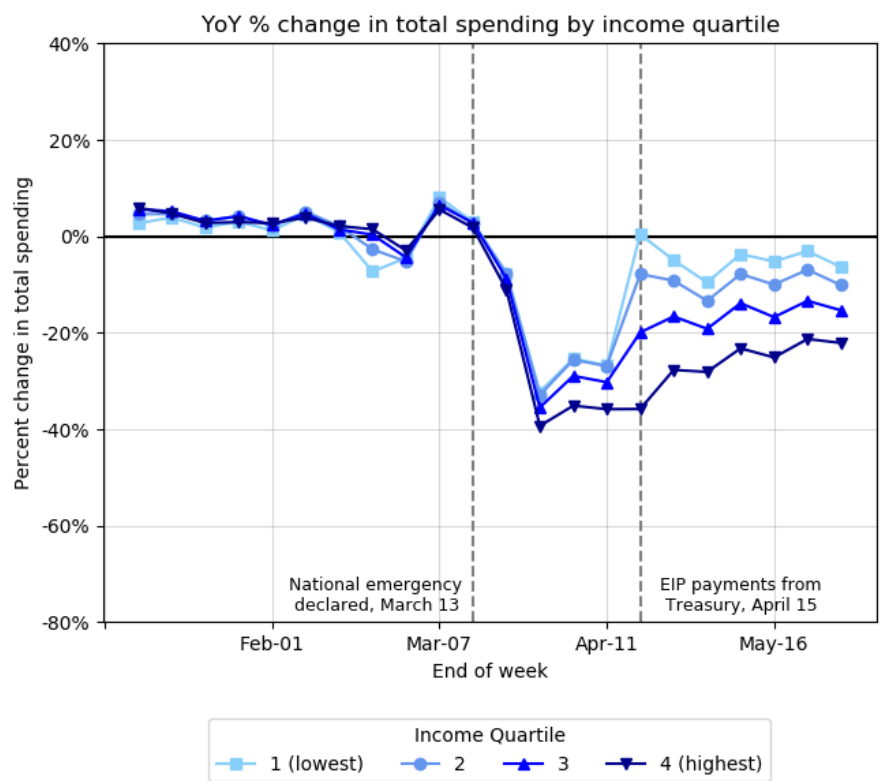

(b) Levels

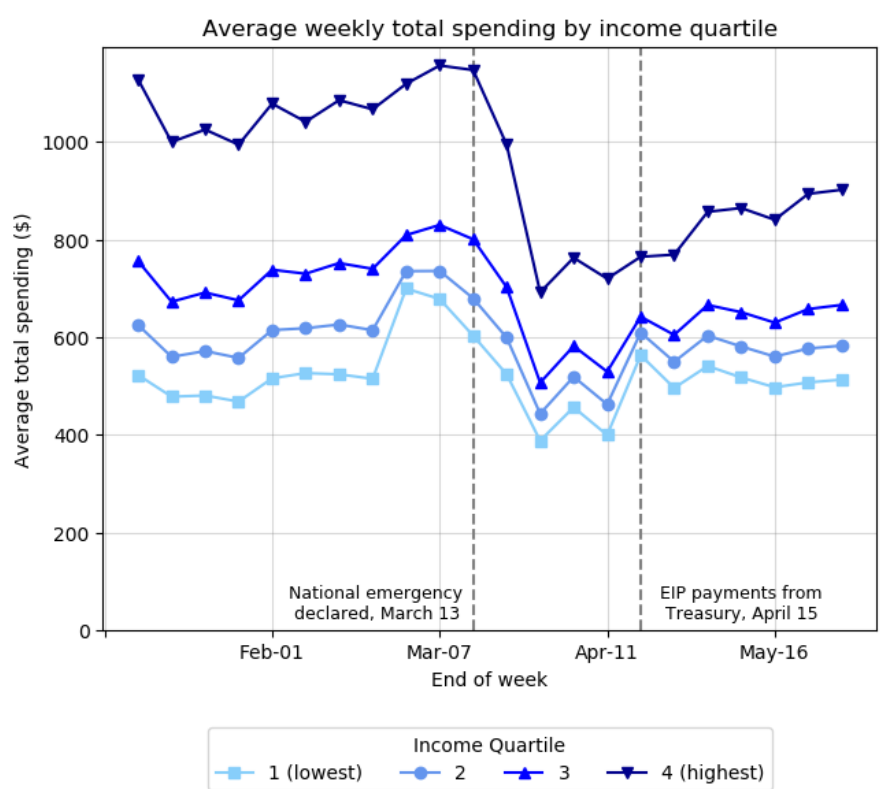

have slower recoveries in spending than low income households, it is important to note that income is correlated with many other factors which might also affect spending responses, so these are not necessarily causal relationships. One particular concern in the context of the pandemic is that income is correlated with physical location, and locations vary in the strength of the pandemic. In particular, high income individuals tend to live in cities, which have greater disease burden and more restrictive shutdowns. This means that the relationship between income and spending dynamics could reflect features of where high income households live, rather than effects of income itself. ${ }^{15}$

To differentiate the role of income from the role of physical location, we look at the relationship between income and spending over the pandemic within narrow geographic areas. In particular, we compute the following regression

$$
\frac{c_{2020, z, q}-c_{2019, z, q}}{c_{2019, q}}=\text { Quartile }_{q}+Z_{I} P_{z}+\varepsilon_{z, q}
$$

where $c_{t, z, q}$ is average spending per customer with $t$ as the year (for the time period April 15May 28), $z$ is zip code and $q$ is the income quartile. We take two steps to minimize the influence

\footnotetext{
${ }^{15}$ Note that measuring spending at the geography rather than household-level introduces additional concerns on this front: high income households are more likely to leave cities than low income households in response to the pandemic, which might induce spurious declines in spending in locations with many high income households prior to the pandemic.
} 
of outliers. First, note that the denominator is $c_{2019, q}$ which uses everyone in the income quartile. This prevents having one very large or very small ratio from skewing our results. Second, $c_{t, z, q}$ is winsorized at the 1st and 99th percentile. We focus primarily on specifications with geography $z$ equal to 5-digit zip codes but also explore more aggregated 3-digit zip codes to again limit the influence of measurement error.

Comparing odd columns without geographic fixed effects to even columns with fixed effects shows that relationships between income and spending over the pandemic within zip codes are very similar to unconditional relationships. That is, high income households cut spending more during the pandemic relative to low income households living in the same zip code. ${ }^{16}$ The similarity of results with and without fixed effects shows that these relationships are not driven by any observed or unobserved differences across locations where high and low income household live.

\section{Table 3: Income-Spend Relationships within Geography}

\begin{tabular}{|c|c|c|c|c|c|c|c|c|}
\hline & \multicolumn{8}{|c|}{ Dependent variable: } \\
\hline & \multicolumn{8}{|c|}{ Spending Growth } \\
\hline & (1) & (2) & (3) & (4) & (5) & (6) & $(7)$ & (8) \\
\hline Income Q2 & $\begin{array}{c}-0.032^{* * *} \\
(0.004)\end{array}$ & $\begin{array}{c}-0.028^{* * *} \\
(0.004)\end{array}$ & $\begin{array}{c}-0.048^{* * *} \\
(0.002)\end{array}$ & $\begin{array}{c}-0.039^{* * *} \\
(0.001)\end{array}$ & $\begin{array}{c}-0.035^{* * *} \\
(0.003)\end{array}$ & $\begin{array}{c}-0.034^{* * *} \\
(0.002)\end{array}$ & $\begin{array}{c}-0.032^{* * *} \\
(0.009)\end{array}$ & $\begin{array}{c}-0.033^{* * *} \\
(0.008)\end{array}$ \\
\hline Income Q3 & $\begin{array}{c}-0.080^{* * *} \\
(0.004)\end{array}$ & $\begin{array}{c}-0.079^{* * *} \\
(0.004)\end{array}$ & $\begin{array}{c}-0.118^{* * *} \\
(0.002)\end{array}$ & $\begin{array}{c}-0.092^{* * *} \\
(0.001)\end{array}$ & $\begin{array}{c}-0.094^{* * *} \\
(0.003)\end{array}$ & $\begin{array}{c}-0.085^{* * *} \\
(0.002)\end{array}$ & $\begin{array}{c}-0.082^{* * *} \\
(0.009)\end{array}$ & $\begin{array}{c}-0.081^{* * *} \\
(0.008)\end{array}$ \\
\hline Income Q4 & $\begin{array}{c}-0.154^{* * *} \\
(0.004)\end{array}$ & $\begin{array}{c}-0.142^{* * *} \\
(0.004)\end{array}$ & $\begin{array}{c}-0.217^{* * *} \\
(0.002)\end{array}$ & $\begin{array}{c}-0.161^{* * *} \\
(0.001)\end{array}$ & $\begin{array}{c}-0.179^{* * *} \\
(0.003)\end{array}$ & $\begin{array}{c}-0.159^{* * *} \\
(0.002)\end{array}$ & $\begin{array}{c}-0.149^{* * *} \\
(0.009)\end{array}$ & $\begin{array}{c}-0.147^{* * *} \\
(0.008)\end{array}$ \\
\hline Constant & $\begin{array}{c}-0.043^{* * *} \\
(0.003)\end{array}$ & & $\begin{array}{c}-0.047^{* * *} \\
(0.001)\end{array}$ & & $\begin{array}{c}-0.049^{* * *} \\
(0.002)\end{array}$ & & $\begin{array}{c}-0.061^{* * *} \\
(0.006)\end{array}$ & \\
\hline Geography FE & $\mathrm{NO}$ & YES & $\mathrm{NO}$ & YES & $\mathrm{NO}$ & YES & $\mathrm{NO}$ & YES \\
\hline Observations & 70,189 & 70,189 & 70,189 & 70,189 & 25,432 & 25,432 & 3,608 & 3,608 \\
\hline Adjusted $\mathrm{R}^{2}$ & 0.024 & 0.235 & 0.238 & 0.557 & 0.137 & 0.506 & 0.082 & 0.272 \\
\hline
\end{tabular}

Table regresses year over year spending growth for the period April 15-May 28, 2020 for individual geography $\times$ income quartiles on income quartile dummies with and without geography fixed effects. Columns (1) and (2) define geography as 5-digit zip codes and equally weight. Columns (3) and (4) use 5-digit zip codes and weight by number of customers in each zip code $\times$ income quartile. Columns (5) and (6) use equal weights and 5-digit zip codes but restrict to zip code $\times$ income quartiles with at least 20 customers. Columns (7) and (8) use equal weights and define geographies as 3-digit zip codes.

Significance: ${ }^{*} p<0.1{ }^{* *} p<0.05,{ }^{* *} p<0.01$.

Finally, we further decompose the decline in credit card spending by income quartiles into

\footnotetext{
${ }^{16}$ Note that our information on address is as-of early 2020.
} 
essential and non-essential categories. ${ }^{17}$ Figures 6 and 7 show that the spending declines for essential categories are indistinguishable across income groups, while non-essential credit card spending diverges more across income groups.

Figure 6: Share of credit card spending decline accounted for by essential and non-essential credit card spending by income quartiles

(a) Essential

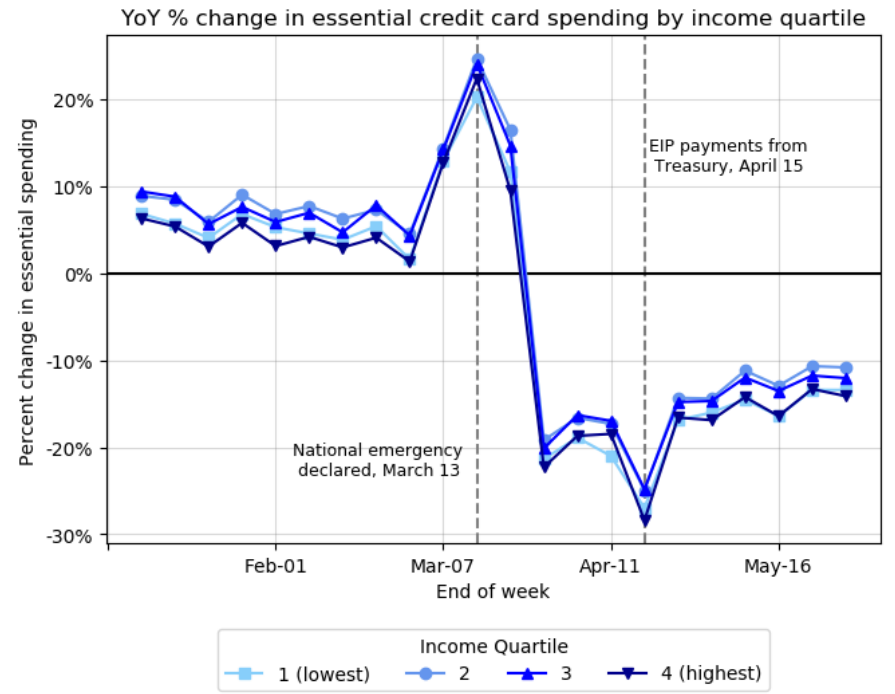

(b) Non-essential

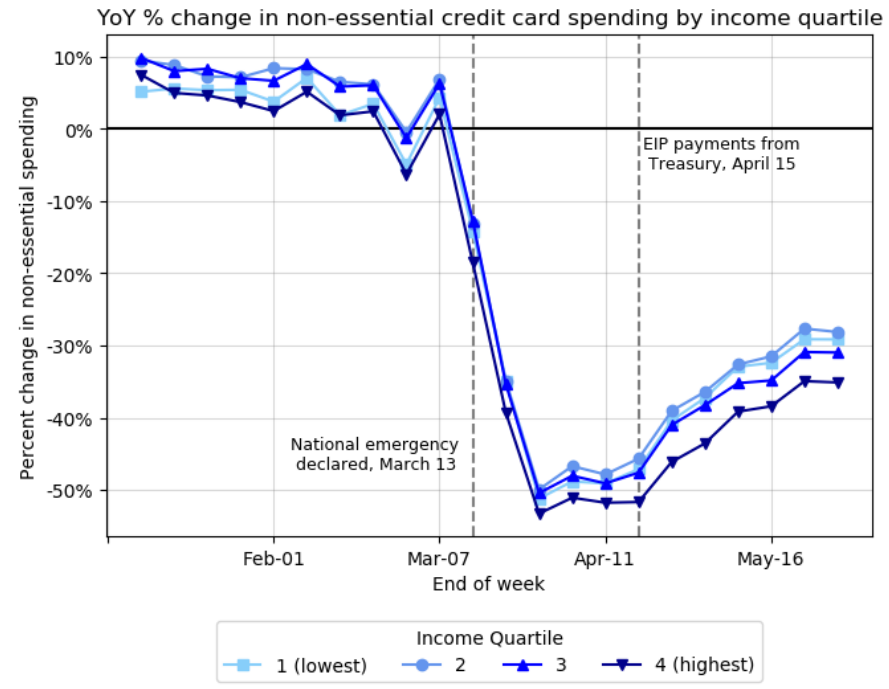

Figure 7: Reduction in essential vs. non-essential spending by income quartiles

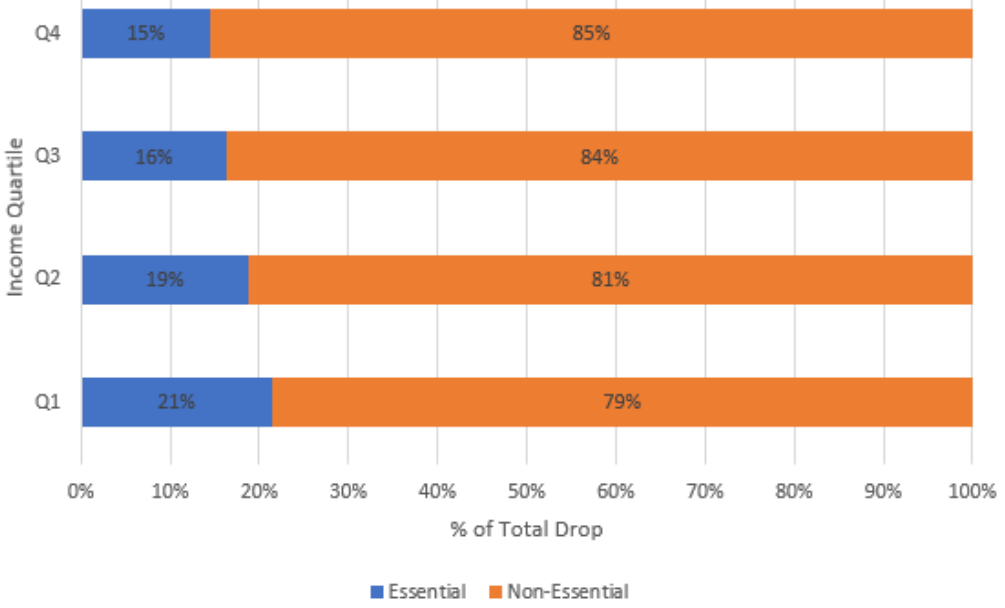

Although all households cut spending dramatically, the fact that high-income households cut spending by somewhat more may be surprising. Recent research suggests that lower-income

\footnotetext{
${ }^{17}$ Unfortunately, as mentioned above, we do not have the spending split by categories for the other forms of payment (debit, cash and check).
} 
households work in jobs that are harder to perform at home, require higher physical proximity, and therefore may be more impacted by distancing restrictions (Mongey, Pilossoph, and Weinberg (2020)). Perhaps as a result, recent evidence from administrative ADP data shows that job losses were four times larger for workers in the bottom income quintile than those in the top income quintile, with a staggering 35 percent employment decline for the lowest-income workers (Cajner et al. (2020)). In response to greater income losses, we might have expected lower-income workers to have cut their spending by more. In fact, we find the reverse: higher-income households cut their spending by slightly more and their spending recovers more slowly.

Differences between high and low-income households in the composition of spending may be one reason why spending falls by more for high-income households. Non-essential categories represent a larger share of spending for high-income households - 67 percent of spending in April 2019 for households in the top income quartile compared to 59 percent for those in the bottom income quartile. In addition, higher-income households have slightly larger drops in their essential spending. Together, these facts imply that reductions in non-essential spending account for a somewhat larger share of total spending declines for high- versus low-income households (85 percent compared to 79 percent, Figure 7). Since these non-essential categories are most affected by the pandemic shut-downs, overall spending of higher-income households may be more affected by supply-side restrictions. In other words, the effective price of consumption rises more for higher-income households relative to lower-income households. Thus, the composition of spending of higher-income households likely contributed to the larger decline in their spending.

As discussed above, the widening of these initial spending declines during the recovery phase may reflect an important role for economic stimulus and transfer programs. The tax rebate checks that began to arrive in April amount to a larger share of total income for a low-income household than for a high-income household. Ganong, Noel, and Vavra (2020) also show that the $\$ 600$ expansion in UI benefits enacted through Federal Pandemic Unemployment Compensation (FPUC) boosted wage replacement rates to well over 100 percent for many low-income unemployed workers, providing a substantial income boost once they began receiving benefits.

Finally, higher-income households may be more exposed to negative wealth effects. Higherincome households hold more financial assets, and therefore are exposed to declines in asset prices during the initial stages of the pandemic. However, wealth effects are unlikely to be a key driver of the heterogeneous spending responses by income, given previous estimates on the strength of wealth effects together with the fact that the stock market had recovered most of its pandemic related losses by the end of May. 


\section{CHANGE IN SPENDING BY INDUSTRY OF EMPLOYMENT}

We next examine whether workers in sectors most affected by employment disruptions adjust spending in ways that differ from workers in less affected sectors.

Figure 8 plots spending changes by industry of employment, for each industry where we have significant sample size. We aggregate to industries at the two-digit NAICS code. The one exception is retail, which we break out into grocery stores, drug stores, and discount stores-generally considered essential businesses and kept open under social distancing policies-and clothing and department stores, which were generally deemed non-essential businesses and where layoffs have been greater (Cajner et al. (2020)).

Overall, it is hard to discern systemic patterns between spending declines and the distribution of employment losses by industries. It is true that essential workers like those in grocery stores exhibit smaller spending declines. At the same time, professionals exhibit the largest spending declines, even though many jobs in this category can more easily be performed remotely.

While industry of employment is closely related to job losses, it is important to note that it is also highly correlated with income levels and that this may be explaining some of these differences. ${ }^{18}$ For example, grocery store workers are typically low income, while professional workers are typically high income. In this sense, patterns when splitting by industry of employment in many ways mirror those when splitting by income: the largest drops and spending and slowest recoveries occur in higher-income industries of employment.

To provide a further sense of the separate role of income and industry, in Figure A.11, we compute spending by industry of employment separately for workers in the highest and lowest quartile of pre-pandemic income. Comparing variation across industries within income quartile in Figure A.11 to variation across industries without conditioning on income in Figure 8 shows that controlling for income substantially reduces the role of industry of employment. Similarly, comparing the same colored line between panels (a) and (b) in Figure A.11 vs. comparing different colored lines in Figure 8 also shows that income generally has a greater correlation with spending dynamics than does industry of employment.

One potential interpretation is that the income channel accounts for only a small share of spending changes through the end of May. This may not be surprising given the magnitude of the spending decline. As mentioned previously, we document that average household spending fell over 35 percent, while the typical unemployed worker receiving UI only cuts spending around 6 percent in normal times (Ganong and Noel (2019)).

However, there are several reasons for caution in concluding that income losses play a small role in spending effects. First, industry of employment may not fully proxy for job loss in our

\footnotetext{
${ }^{18}$ See Appendix Table A.2.
} 
Figure 8: Spending Changes Split by Industry of Employment

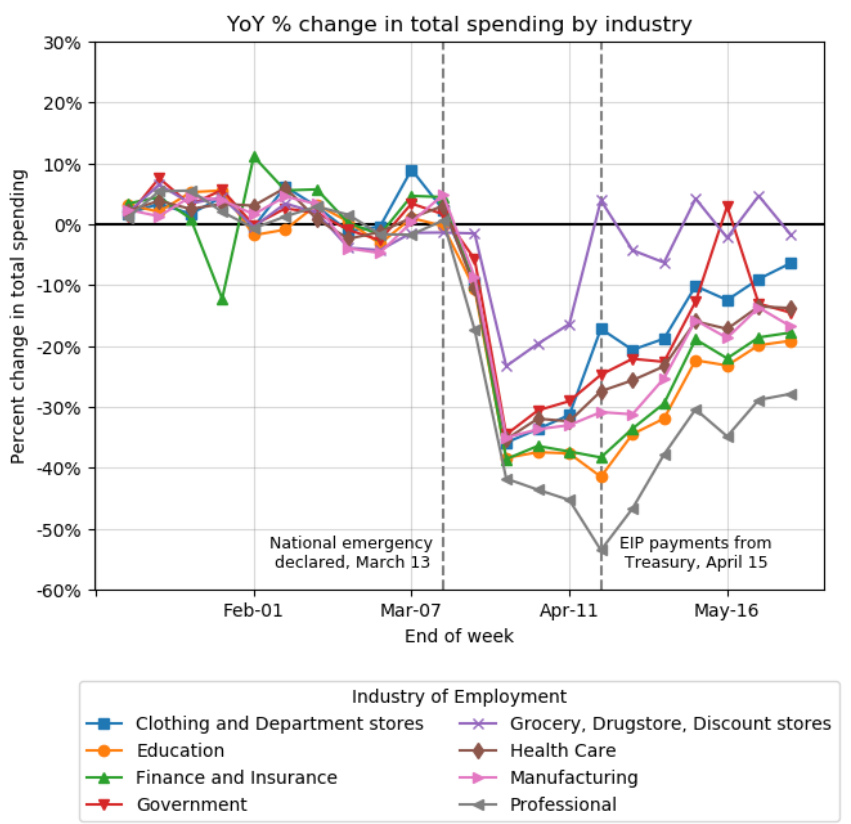

sample. To the extent that we can ascertain industry of employment primarily for employees of large firms, we may not be capturing the income losses for employees of small businesses.

Second, current conditions of the pandemic make comparing the magnitude of the spending response in April 2020 to that of UI recipients during normal times highly uncertain. On the one hand, the economic situation is highly uncertain, and labor markets weakened at an unprecedented pace. This might cause the unemployed to cut spending by more than during normal unemployment spells. On the other hand, as a result of the CARES Act, UI benefits are much more generous in level and duration, and available to many more workers. Furthermore, sizable stimulus checks were also sent out in April. These income supports might buffer against labor income-related spending declines if this stimulus continues. The more rapid recovery of spending for low-income households suggest this channel is at work. The rest of the paper looks at the behavior of household savings to provide additional evidence on these channels.

\section{Household Liquid Balances}

Given the unprecedented reduction in spending across income and industries documented above, we next explore whether there were changes in the distribution of household liquid balances. Figure 1 shows that aggregate private savings increased substantially over the pandemic, reflecting the combination of large declines in spending and large increases in government transfers from stimulus programs. However, there are reasons to think that the pandemic could have hetero- 
geneous impacts on household savings and substantial resulting effects on the distribution of wealth: households experiencing job loss may draw down on savings (or further draw on sources of borrowing), while those with job security may be essentially forced to save more, as consumption of many non-essential goods and services is more restricted. In addition, stimulus payments and other income support programs represent a larger share of pre-pandemic income for highthan for low-income households.

To explore these effects, we calculate how the distribution of end-of-week balances in household checking accounts evolved during the pandemic. Specifically, we explore how various unconditional moments of checking account balances evolved as well as how balances changed across the income distribution and by industry of employment. While checking account balances are only a subset of total savings and wealth, they represent some of the most liquid and easily accessible "cash-on-hand" available for households to smooth consumption and self-insure. A large literature has shown that liquid assets of this form play a crucial role in consumption. Furthermore, checking account balances have the practical advantage of being precisely and easily measured since checking accounts are one of our primary data sources.

We begin by plotting the average level of liquid balances, and the percentage year-over-year change from January through the end of May 2020. Figure 9 shows that by the last week of May, average balances increased by 33 percent year-over-year, or about $\$ 1500$ dollars relative to earlier in the year. This increase is consistent with the large increase in the personal savings rate shown in Figure 1 and with the growth in the stock of commercial bank deposits shown in Appendix Figure A.13. ${ }^{19}$ Much of the year-over-year growth in checking balances occurred during and after the week when most EIP stimulus checks were deposited, which suggests that the increase was driven by these income inflows, in addition to the reduced spending we documented in the previous section. ${ }^{20}$

Figure 10 plots additional moments of the distribution of liquid balances over time. Panel (a) shows that increases in liquid balances are pervasive, with increases observed at various percentiles of the distribution. The dollar increase in balances is greater for households with larger initial pre-pandemic balances. However, it is important to note that scale effects would be expected to drive that type of pattern: for example, if all balances double, the accounts with the largest initial balances will have the largest absolute increases. Panel (b) shows that the lower end of the distribution is growing more than the top end of the distribution. Interestingly, the yearover-year growth for lower percentiles shoots up around the time of stimulus payments and then

\footnotetext{
${ }^{19}$ Note that Figure 9 should not be compared directly to the personal savings rate in Figure 1, since aggregate personal savings is a flow variable while checking account balances are a stock variable. Appendix Figure A.13 provides evidence on the growth in a more comparable aggregate stock variable to Figure 9.

${ }^{20}$ We further decompose this trend into checking account inflows and outflows in the Appendix.
} 
Figure 9: Level and Year-on-Year Change in Average Checking Account Balances.

(a) Levels

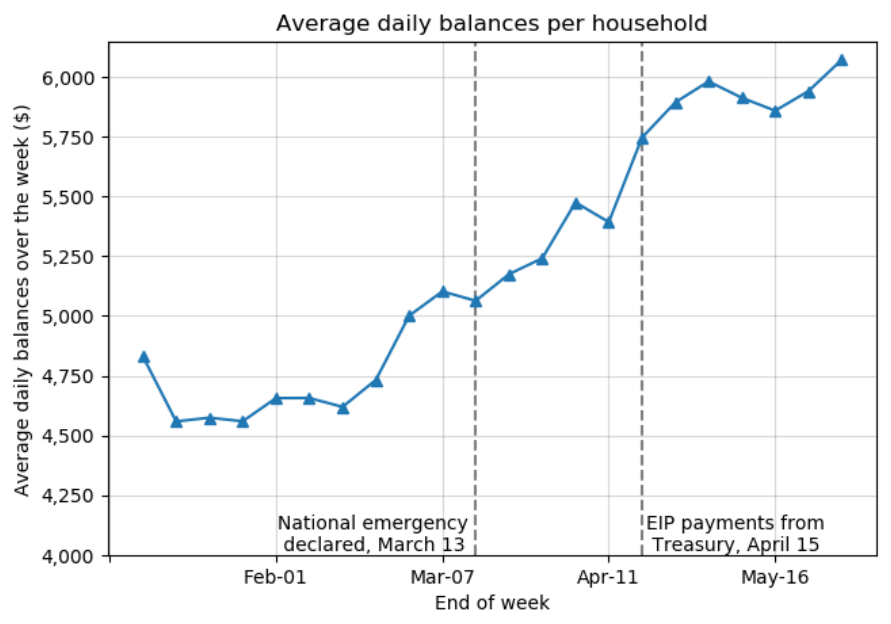

(b) Percent Change

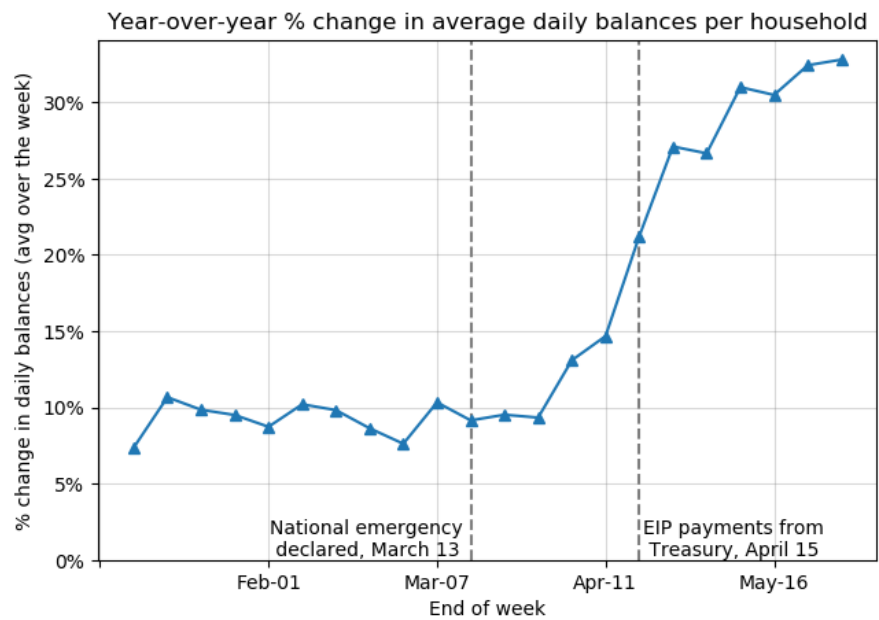

trends down. This suggests that households with low initial liquidity received a large increase in liquidity from stimulus payments, but they may be fairly rapidly using up this additional cash.

Figure 10: Change in Distribution of Checking Account Balances.

(a) Levels

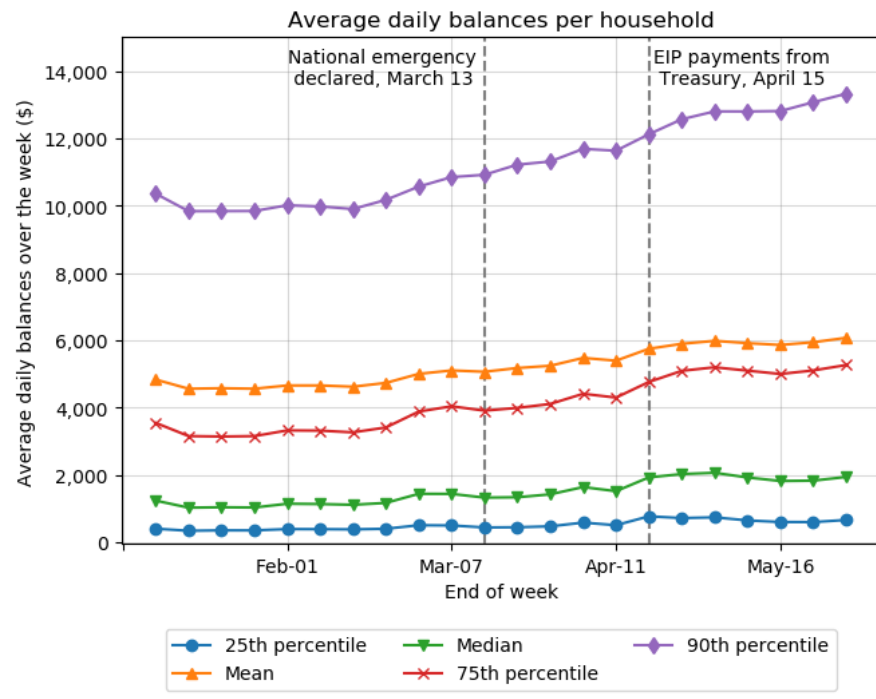

(b) Percent Change

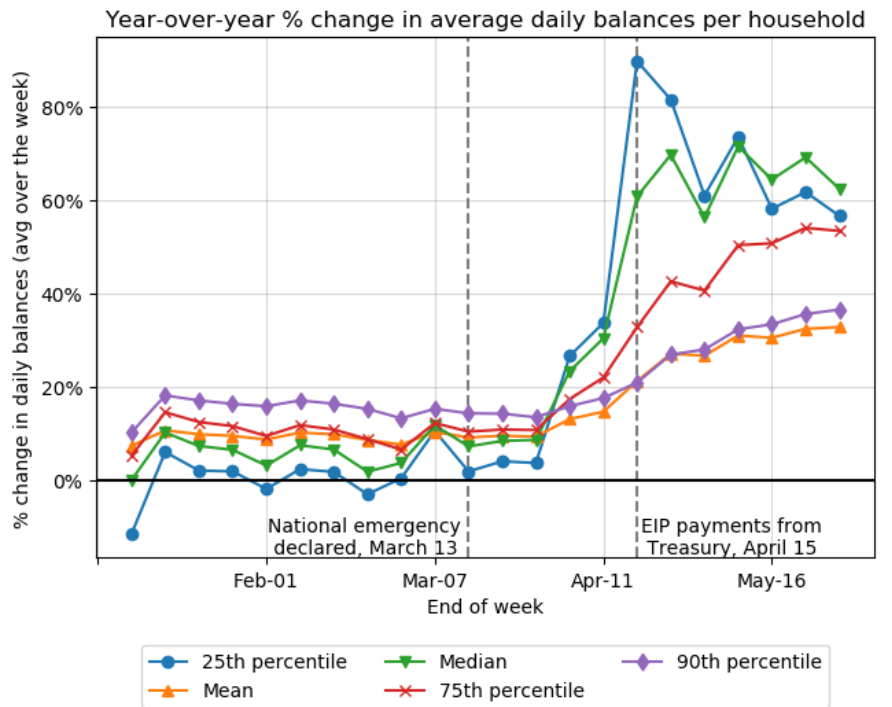

While the results in Figure 10 show that increases in liquid balances are pervasive, it is interesting to explore the relationship with pre-pandemic income. In particular, it is useful to know 
whether the increase in aggregate liquid balances was primarily driven by gains at the top of the income distribution (e.g. by individuals who cut spending most dramatically while generally maintaining labor income), or by gains at the bottom of the income distribution (e.g. individuals who cut spending somewhat less and faced larger declines in labor market income - but also had larger government transfers). Figure 11 plots checking account balances (in levels and growth rates) by income quartiles. Similar to the unconditional distribution of balances, we see pervasive increases in balances with increases observed for all groups. Also similar to the unconditional distribution, there are clear scale effects: the highest income quartile posted the largest dollar gains of around $\$ 2,000$. The lowest income quartile increased balances by more than $\$ 1,000$, which was the largest increase in year-on-year percentage terms.

Figure 11: Change in Average Checking Account Balances by Income Quartile.

(a) Levels

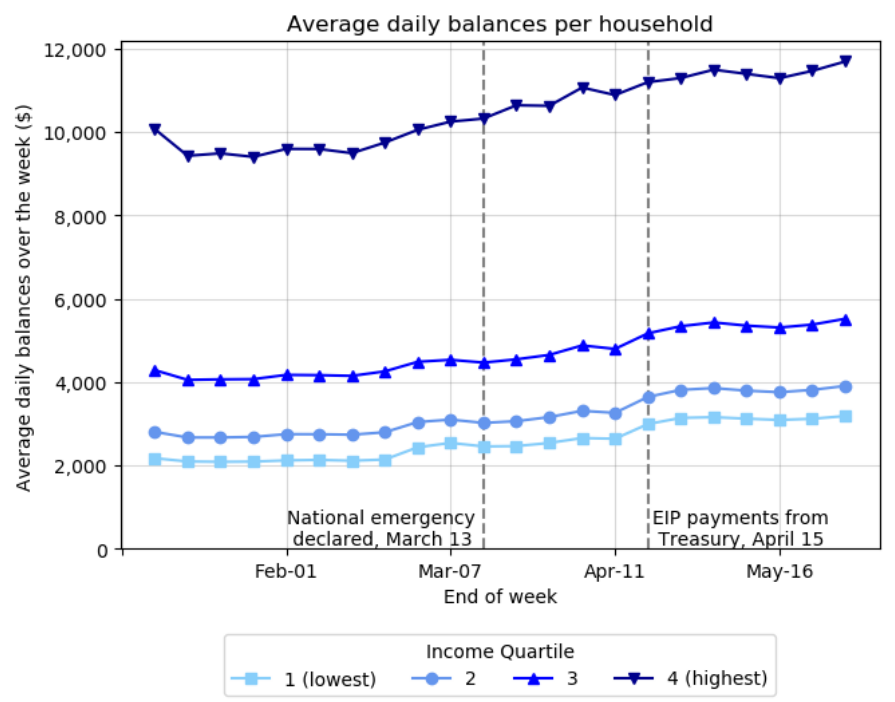

(b) Percent Change

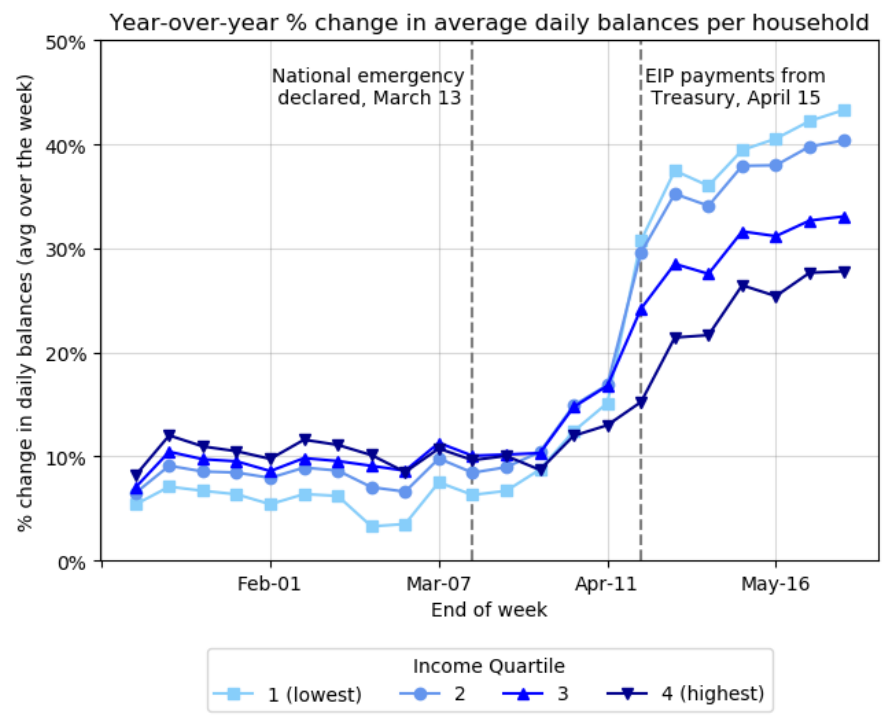

This figure plots both average dollar balances and year-on-year percentage change in checking account balances by income quartile. Balance increases are larger in dollar terms for high-income households (who have higher preCOVID balances), and in percent terms for low-income households (who have lower pre-COVID balances).

Given these scale effects, what should we conclude about the relative role of high- vs. lowincome households in driving the increase in liquid wealth? One way to answer this question is to compare each group's contribution to the aggregate increase, relative to that group's initial share of savings. If all groups savings grow by the same amount, then each group's contribution to the aggregate increase is equal to its initial share and the wealth distribution is unchanged. If lowincome households have higher savings growth, then they will contribute more to the aggregate increase than their initial share and wealth inequality will decline. 
Table 4: Decomposition of Total Liquid Balances Changes by Income Quartile

\begin{tabular}{|c|c|c|c|c|c|c|}
\hline & $\begin{array}{c}\text { Initial } \\
\text { Balances }\end{array}$ & $\begin{array}{l}\text { Share of } \\
\text { Initial } \\
\text { Balances }\end{array}$ & $\begin{array}{c}\text { Increase in } \\
\text { Balances }\end{array}$ & $\begin{array}{c}\text { Share of } \\
\text { Increase in } \\
\text { Balances }\end{array}$ & $\begin{array}{c}\text { Final } \\
\text { Balances }\end{array}$ & $\begin{array}{c}\text { Share of } \\
\text { Final } \\
\text { Balances }\end{array}$ \\
\hline Quartile 1 & $\$ 2.67 \mathrm{~B}$ & $11.4 \%$ & $\$ 1.28 \mathrm{~B}$ & $19.0 \%$ & $\$ 3.95 B$ & $13.1 \%$ \\
\hline Quartile 2 & $\$ 3.44 \mathrm{~B}$ & $14.7 \%$ & $\$ 1.39 \mathrm{~B}$ & $20.7 \%$ & $\$ 4.83 B$ & $16.1 \%$ \\
\hline Quartile 3 & $\$ 5.22 \mathrm{~B}$ & $22.3 \%$ & $\$ 1.60 \mathrm{~B}$ & $23.8 \%$ & $\$ 6.82 \mathrm{~B}$ & $22.7 \%$ \\
\hline Quartile 4 & $\$ 12.02 B$ & $51.5 \%$ & $\$ 2.45 B$ & $36.4 \%$ & \$14.47B & $48.1 \%$ \\
\hline Total & $\$ 23.35 B$ & $100.0 \%$ & $\$ 6.72 B$ & $100.0 \%$ & $\$ 30.07 \mathrm{~B}$ & $100.0 \%$ \\
\hline Top Decile & $\$ 7.19 B$ & $30.8 \%$ & $\$ 1305 \mathrm{M}$ & $19.4 \%$ & $\$ 8.49 B$ & $28.2 \%$ \\
\hline Top One Percent & $\$ 1.84 \mathrm{~B}$ & $7.9 \%$ & $\$ 294 M$ & $4.4 \%$ & $\$ 2.13 B$ & $7.1 \%$ \\
\hline
\end{tabular}

Initial balances are computed in February 2020 and Final Balances are calculated in May 2020.

To explore this more formally, Table 4 reports the initial balances in February 2020, the increase in balances from February to May, and the final balances in May for each income quartile. Unsurprisingly, higher income quartiles contribute more to the level and change in total liquid balances, since these households have much more liquid wealth. For example, 51.5\% (12.02/23.35) of total liquid balances come from the top income quartile.

It is also true that the top income quartiles drive the majority of the increase in liquid balances over the pandemic $(36 \%)$, but importantly, this increase is less than proportional to the initial share of liquid wealth held by the top quartile. Table 4 shows that lower-income quartiles are actually driving more of the aggregate increase in balances than would be expected from their initial balance shares, so liquid wealth inequality decreases between February and May. This provides a concrete sense in which the poor are disproportionately increasing savings relative to the rich during this pandemic. While this shift in the wealth distribution towards low-income households many not seem huge, it implies a more than three percentage point decline in the share of liquid wealth held by the richest quartile occurring over a matter of weeks. One important caveat is that we only measure checking account balances. If higher-income households transferred more assets out of the checking account, it is possible that we understate the increase in their total assets. ${ }^{21}$

This increase in savings for the poor very likely reflects the fact that stimulus checks and expanded UI benefits provide a disproportionate increase in income for these households. This also means that this shift may reverse in the near future if stimulus is reduced. For example, the expanded federal supplement to UI insurance which has led to replacement rates above $100 \%$ for many families, is set to expire at the end of July 2020. The magnitude of the additional spending drop induced by initial disease avoidance and social distancing restrictions may also dominate the consumption response caused solely by income loss. This could lead to an increase in savings, even for those experiencing job loss, but it might not continue as social distancing is relaxed.

\footnotetext{
${ }^{21}$ On the other hand, if delayed tax payments contributed to the growth in cash balances among high-income families, liquid asset growth could be short-lived.
} 
Figure 12: Growth of Balances by Industry of Employment

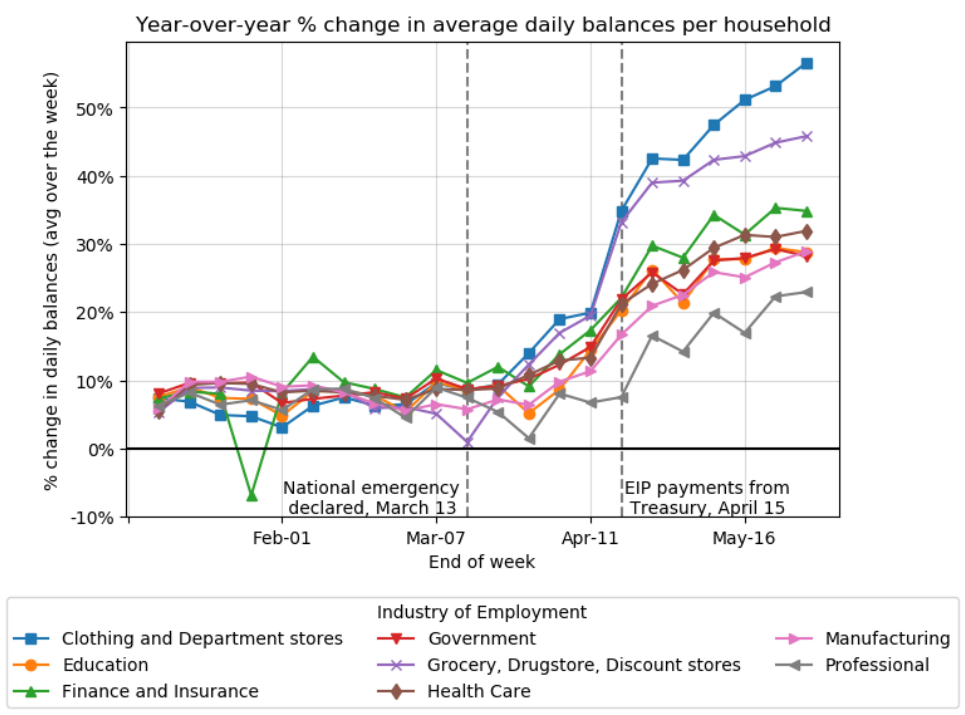

Finally, Figure 12 shows liquid balance growth by industry of employment. While increases are again pervasive, we find that grocery store and department store workers have the largest growth in checking account balances. This is directly in line with checking account growth by income, since these are also the lowest income industries in our split.

\section{Conclusion}

We find that all individuals across the income distribution cut spending at the start of the pandemic. These declines are massive relative to typical responses to spending responses to unemployment. While high-income households cut spending more than low-income households, these differences are small relative to the huge common declines in spending. However, beginning in mid-April, substantial differences by income emerge: while spending begins to recover for all groups, it does so much more rapidly for the lowest income quartile. Similar patterns emerge when cutting by industry of employment, with workers in all industries initially cutting spending dramatically and then workers in low wage industries seeing spending recover more quickly.

One limitation of this paper is that Chase micro data on income during the pandemic period is still being processed at the time of writing and not yet available for analysis. We therefore turn to public use data to explore how the income distribution has changed in recent months. Specifically, we simulate how income has likely changed in the first few months of the pandemic using statutory provisions of the CARES Act, information from the Current Population Survey, and the unemployment insurance calculator in Ganong, Noel, and Vavra (2020). Although labor income fell the most for lower-income households, we estimate that total income including transfers actu- 
ally increased the most for those at the bottom of the income distribution for two reasons. First, the EIPs were a flat payment and therefore constituted a larger share of income for low-income households. Second, because the temporary $\$ 600$ supplement to UI benefits under the CARES Act is the same for all unemployed workers, it drives up the replacement rate and resulting income disproportionately for low income workers. In fact, UI benefits now replace more than 100 percent of lost earnings for low-income households (Ganong, Noel, and Vavra (2020)). The details of this simulation are described in the Appendix.

Figure 13: Estimated changes in income and spending by income quartiles

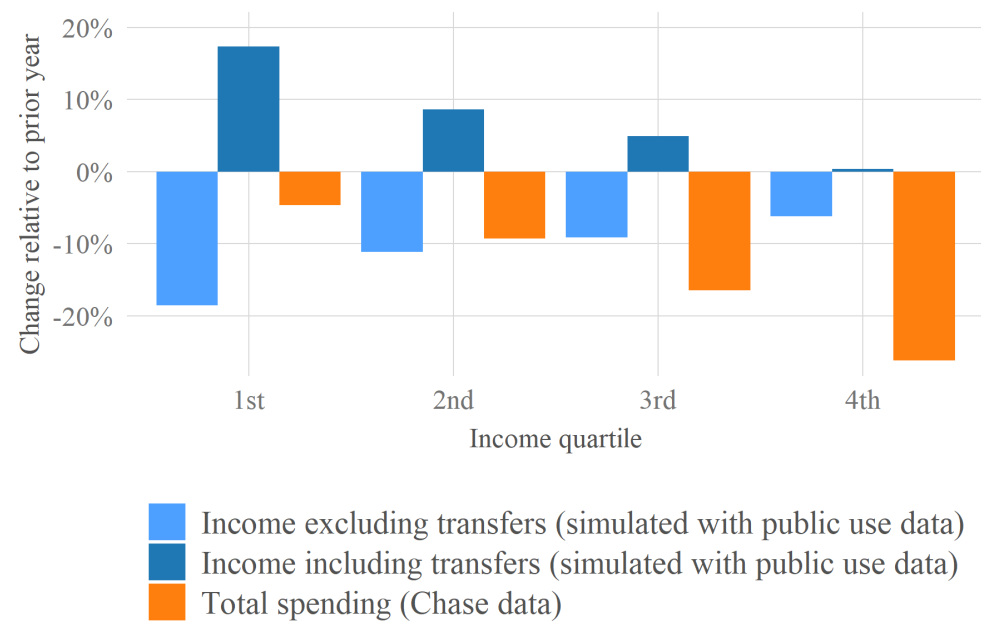

This figure shows the change in income and spending by income quartile. The change in income compares March, April, and May 2020 to average quarterly income in the prior year. The change in income reflects the decline in labor income, the EIPs, and unemployment benefits. The change in spending compares April 15-May 30 to spending at the same time in the prior year. Our estimate focuses on this narrower time horizon after the most immediate impacts of the lockdown—which depressed spending across the income distribution-had subsided.

Figure 13 juxtaposes simulation-based estimates of the change in income alongside the change in spending from Figure 2. There is a suggestive correlation between the pattern of income changes and the relative pattern of spending changes. Spending falls the least for the group receiving the most income support, and decreases the most for the group with the least income support. In future work, when Chase micro data on income during the pandemic becomes available, we plan to explore the joint dynamics of income and spending at the household-level to better understand these patterns.

Two other pieces of evidence in our paper suggest that government income support could be driving spending during this period. First, the timing of the more rapid rebound in spending for low-income households coincides closely with the timing of EIP stimulus and expanded UI benefits, suggesting an important role for government support in stabilizing spending during the pandemic, especially for low-income workers. Second, while increases in liquid balances are widespread during the pandemic and driven in large part by general declines in spending, we 
see that households at the bottom end of the income distribution -who see the largest stimulus relative to pre-pandemic income - have the largest growth in liquid savings during this period. As a result, liquid wealth inequality falls between February and May.

Taken together, our results suggest that labor market disruptions were unlikely to be a primary factor driving spending declines in these initial months of the recession. Many of the effects of labor market disruptions on spending were likely offset by sizable fiscal stimulus and insurance programs. Instead, direct effects of the pandemic were likely the primary factor driving overall declines in spending. Our analysis does not claim to disentangle the effect of pandemicrelated channels - i.e regulatory shut-downs vs. disease prevalence and fear of infection - on the spending decline. It instead focuses on the impact of income changes brought about by job loss and government transfers.

There are some important cautionary implications for future policy. First, it is important to note that even though aggregate spending has recovered substantially from its nadir, it remains well below normal. Spending on May 31st, when our sample currently ends, remains very low in absolute terms, even when compared to spending declines in other severe episodes like the Great Recession. Spending has partially recovered, but still remains severely depressed relative to pre-pandemic levels. Policy makers should thus not be too quick to conclude that the economy has rapidly recovered to normal. Even more importantly, our results suggest that an important share of this spending recovery has in fact been driven by aggressive fiscal stimulus and insurance payments. While we see a large spike in savings for low-income households immediately after EIP, these increases may erode as the EIP gets used and if UI benefits get scaled back. This suggests that new support may be needed to maintain spending for low-income, vulnerable households in the near future. Phasing out broad stimulus too quickly could potentially transform a supply-side recession driven by direct effects of the pandemic into a broader and more persistent recession caused by declines in income and aggregate demand.

\section{References}

Alexander, Diane and Ezra Karger. 2020. “Do Stay-at-Home Orders Cause People to Stay at Home? Effects of Stay-at-Home Orders on Consumer Behavior." Tech. Rep. WP 2020-12, Federal Reserve Bank of Chicago.

Andersen, Asger, Emil Hansen, Niels Johannesen, and Adam Sheridan. 2020. "Pandemic, Shutdown and Consumer Spending: Lessons from Scandinavian Policy Responses to COVID-19."

Baker, Scott R, R.A. Farrokhnia, Steffen Meyer, Michaela Pagel, and Constantine Yannelis. 2020. "How Does Household Spending Respond to an Epidemic? Consumption During the 2020 
COVID-19 Pandemic." Working Paper 26949, National Bureau of Economic Research. URL http://www. nber.org/papers/w26949.

Bitler, Marianne, Hilary Hoynes, and Diane Schanzenbach. (2020). "The social safety net in the wake of COVID-19. BPEA Conference Drafts." Tech. rep.

Cajner, Tomaz, Leland Dod Crane, Ryan Decker, John Grigsby, Adrian Hamins-Puertolas, Erik Hurst, Christopher Johann Kurz, and Ahu Yildirmaz. 2020. "The U.S. Labor Market During the Beginning of the Pandemic Recession." Tech. Rep. WP 2020-58, University of Chicago, Becker Friedman Institute for Economics.

Chetty, Raj, John N. Friedman, Nathaniel Hendren, Michael Stepner, and the Opportunity Insights Team. 2020. "How Did COVID-19 and Stabilization Policies Affect Spending and Employment? A New Real-Time Economic Tracker Based on Private Sector Data."

- accessed on 06/15/2020. Economic Tracker. https: //tracktherecovery . org/.

EarnestResearch. 2020. Where States Stand: Measuring the Reopenings One Step at a Time. https://www.earnestresearch.com/insights/ where-states-stand-measuring-the-reopening-one-step-at-a-time/.

Facteus. accessed on 06/15/2020. Insights on Changing Consumer Spending. Facteus Insight Report on Consumer Spending and Transactions. https://www. facteus.com/reports/ first-report-6-10-2020/.

Ganong, Peter and Pascal Noel. 2019. "Consumer Spending during Unemployment: Positive and Normative Implications." American Economic Review 109 (7):2383-2424. URL https: / /www . aeaweb.org/articles?id=10.1257/aer.20170537.

Ganong, Peter, Pascal Noel, and Joseph Vavra. 2020. “US Unemployment Insurance Replacement Rates During the Pandemic." Tech. Rep. WP 2020-62, University of Chicago, Becker Friedman Institute for Economics.

Karger, Ezra and Aastha Rajan. 2020. "Heterogeneity in the Marginal Propensity to Consume: Evidence from Covid-19 Stimulus Payments." Tech. Rep. WP 2020-15, Federal Reserve Bank of Chicago.

Mongey, Simon, Laura Pilossoph, and Alex Weinberg. 2020. "Which Workers Bear the Burden of Social Distancing Policies?" Tech. Rep. WP 2020-51, University of Chicago, Becker Friedman Institute for Economics. 


\section{APPENDIX}

\section{Natalie Cox Peter Ganong Pascal Noel Joseph Vavra Arlene Wong Diana Farrell Fiona Greig}

\section{A.1 Change in Spend by Payment Type}

Figure A.1: Average Spending Changes on Credit Cards

(a) Percent Change

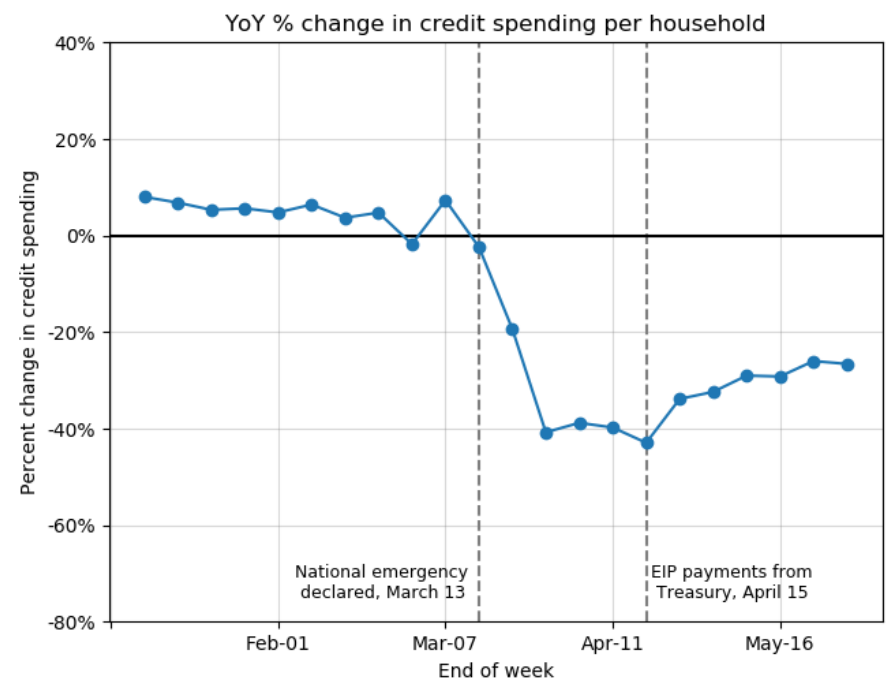

(b) Levels

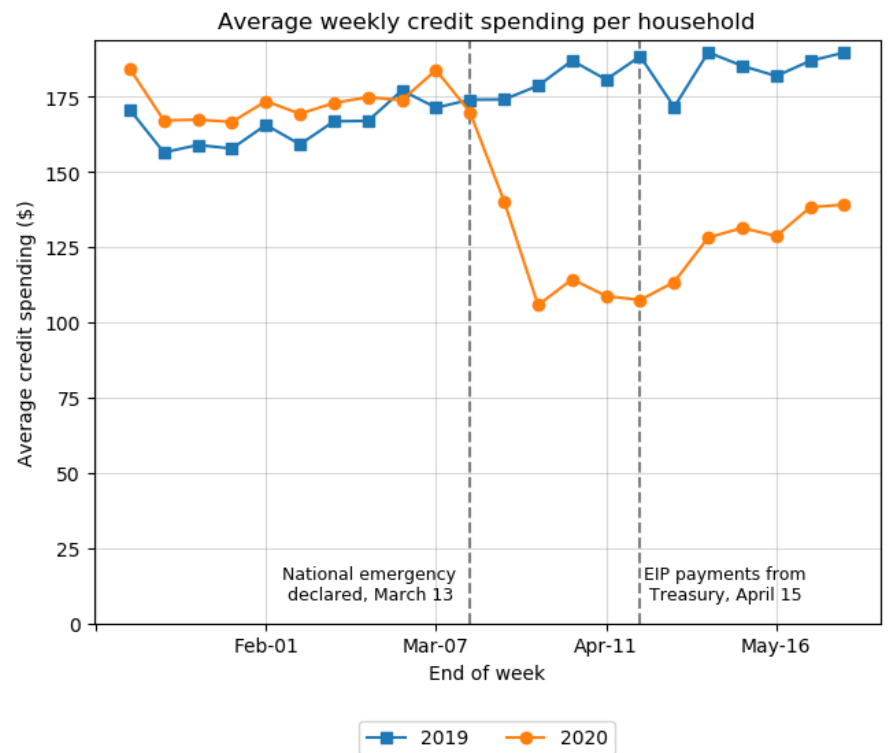

The left panel plots the year-over-year percentage change in weekly credit card spending. The right panel plots the dollar change in weekly credit card spending. 
Figure A.2: Average Spending Changes on Debit Cards

(a) Percent Change

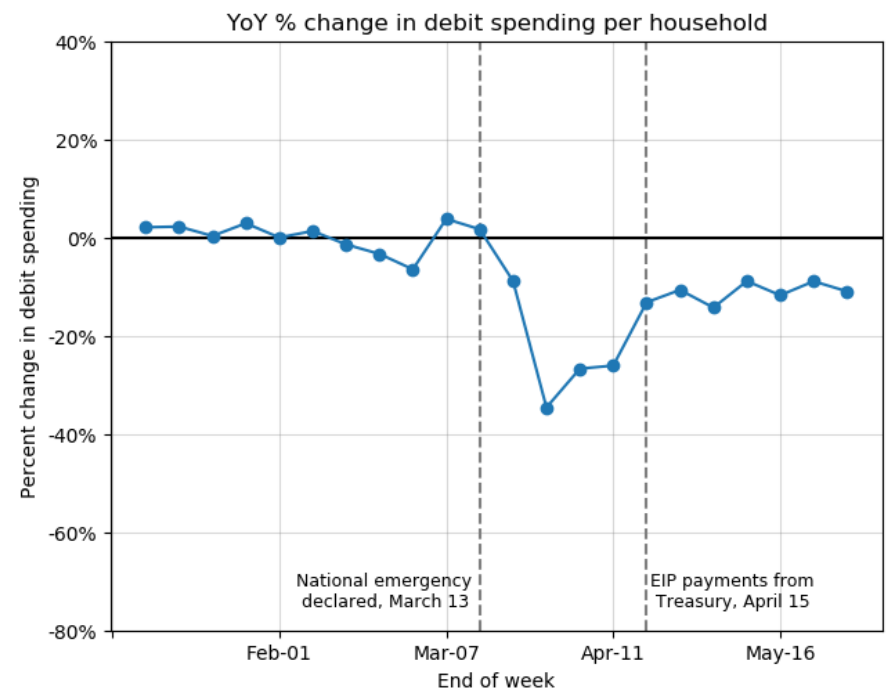

(b) Levels

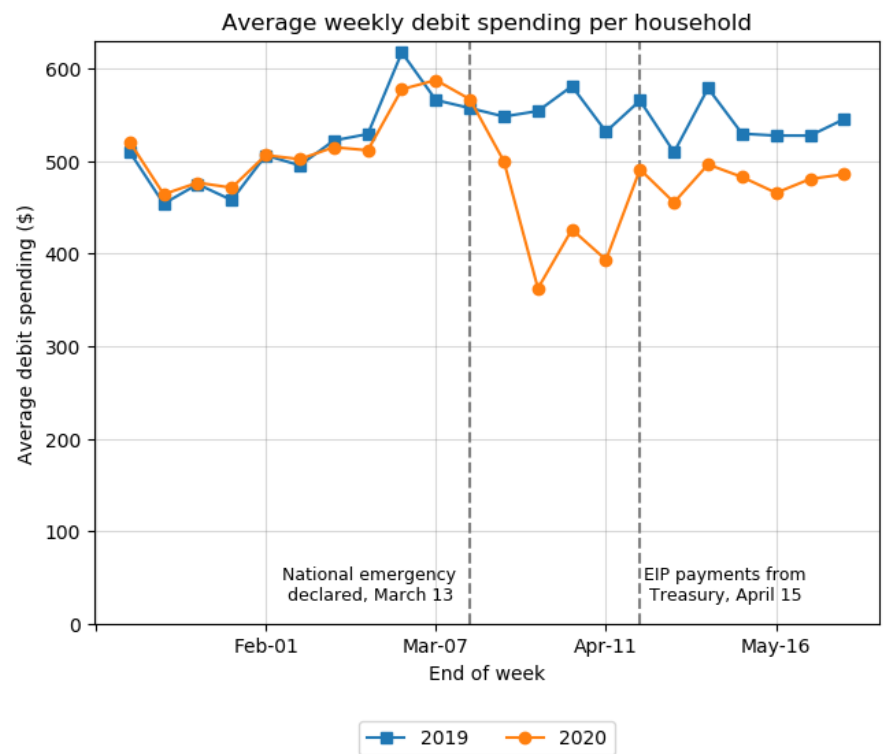

The left panel plots the year-over-year percentage change in weekly debit card spending. The right panel plots the dollar change in weekly debit card spending. Here we demarcate the date of the first EIP payments from Treasury. Over 50\% total EIP payments were distributed by April 17 (see https://home.treasury.gov/news/pressreleases/sm1025). Therefore, while the delivery of EIP payments was somewhat "staggered" over time, the majority were received close to this point in time.

\section{Figure A.3: Average Changes in Cash Spending}

(a) Percent Change

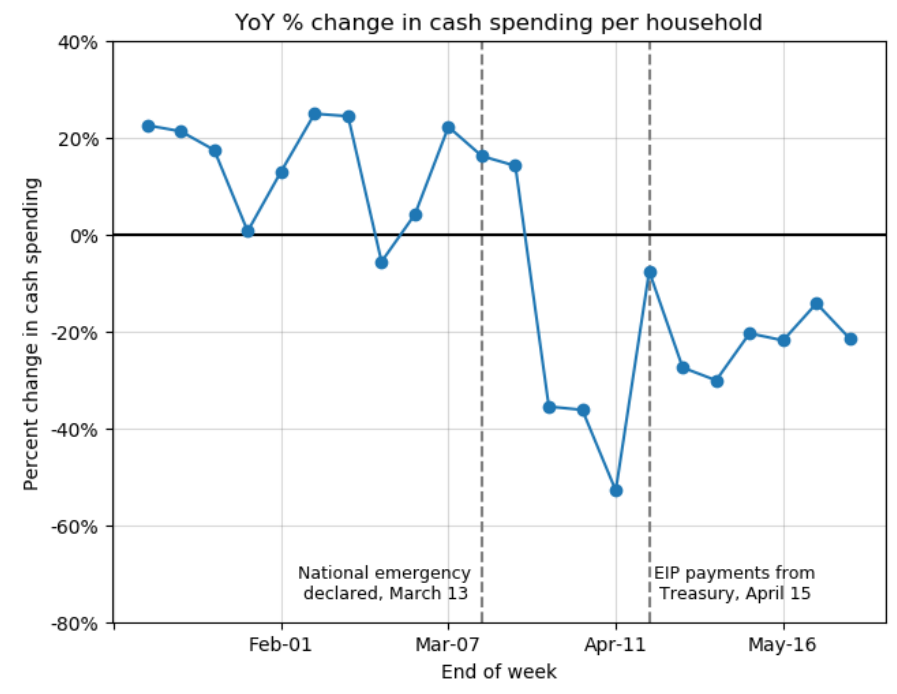

(b) Levels

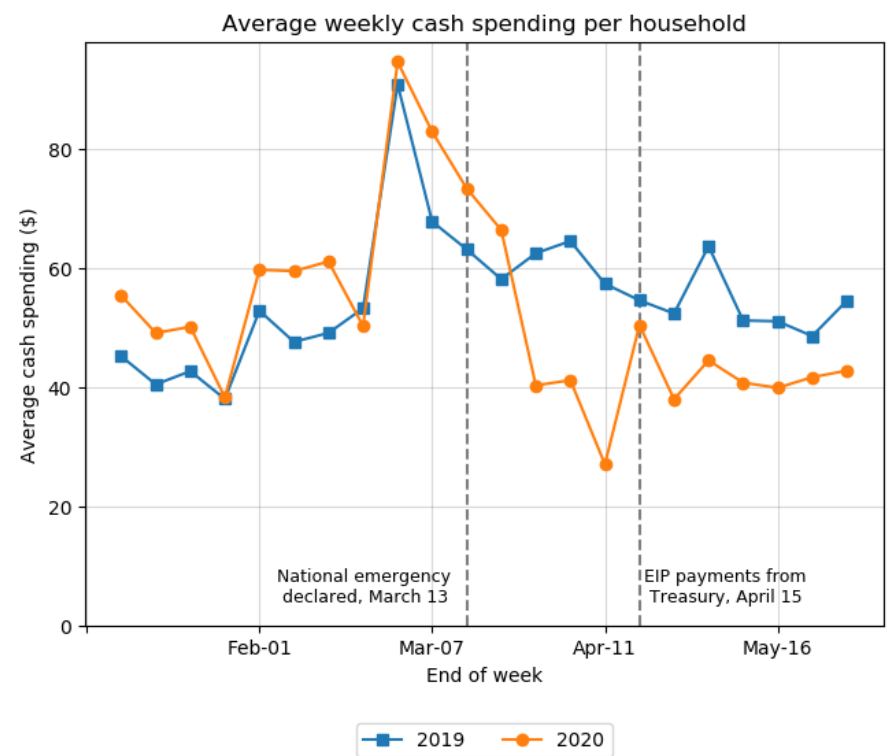

The left panel plots the year-over-year percentage change in weekly cash withdrawals. The right panel plots the dollar change in weekly cash withdrawals. Cash withdrawals at ATMs using debit cards are reflected in the debit card series, so this series primarily reflects cash withdrawals with bank tellers. 


\section{Figure A.4: Average Spending Changes in Checks}

(a) Percent Change

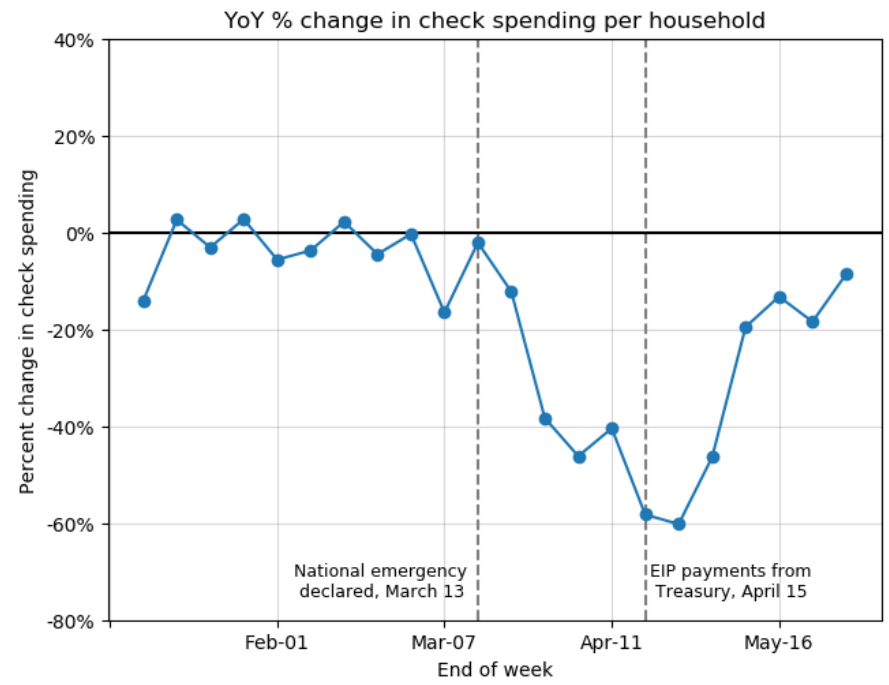

(b) Levels

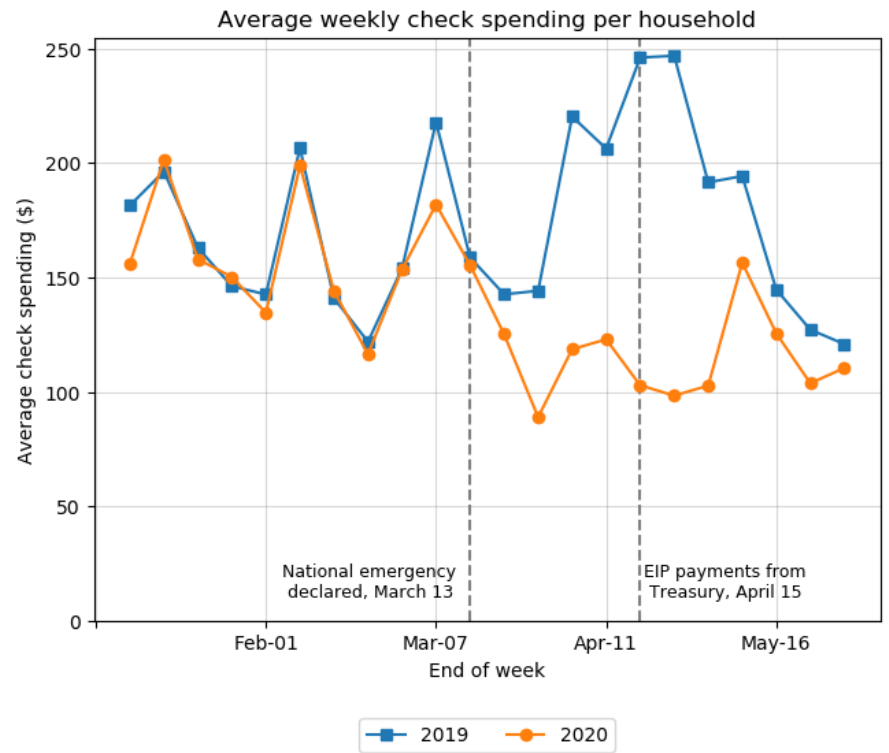

The left panel plots the year-over-year percentage change in weekly spending via checks. The right panel plots the dollar change in weekly spending via checks.

Figure A.5: Average Total Spending Changes (Including Check Spending)

(a) Percent Change

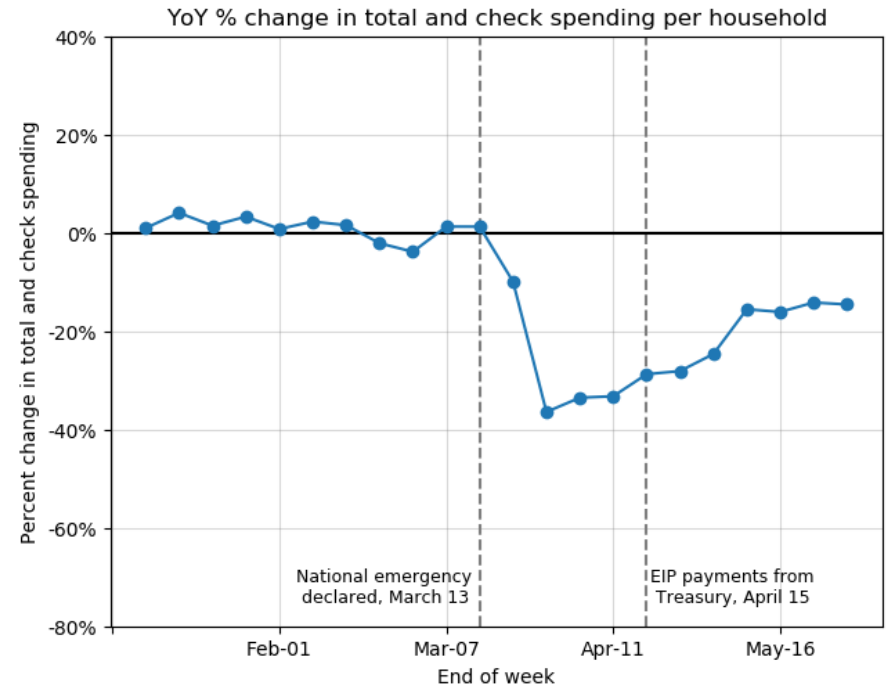

(b) Levels

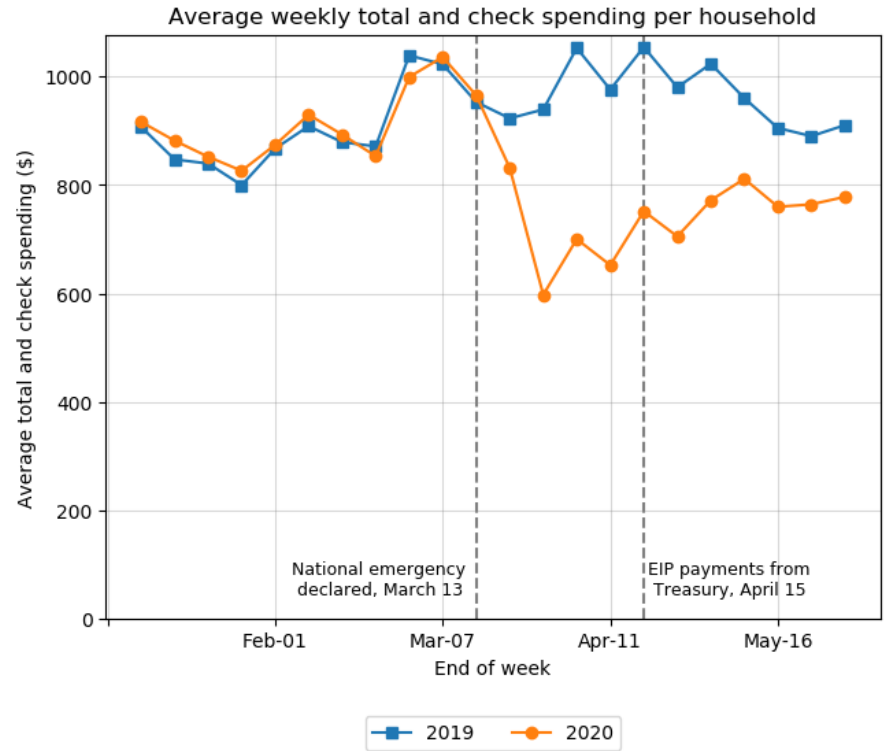

The left panel plots the year-over-year percentage change in weekly total spending (inclusive of spending via checks). The right panel plots the dollar change in weekly total spending (including spending via checks). 


\section{A.2 Spending by Payment Type, Split by Income Quartiles}

Figure A.6: Credit card spending by income quartiles

(a) Percent Change

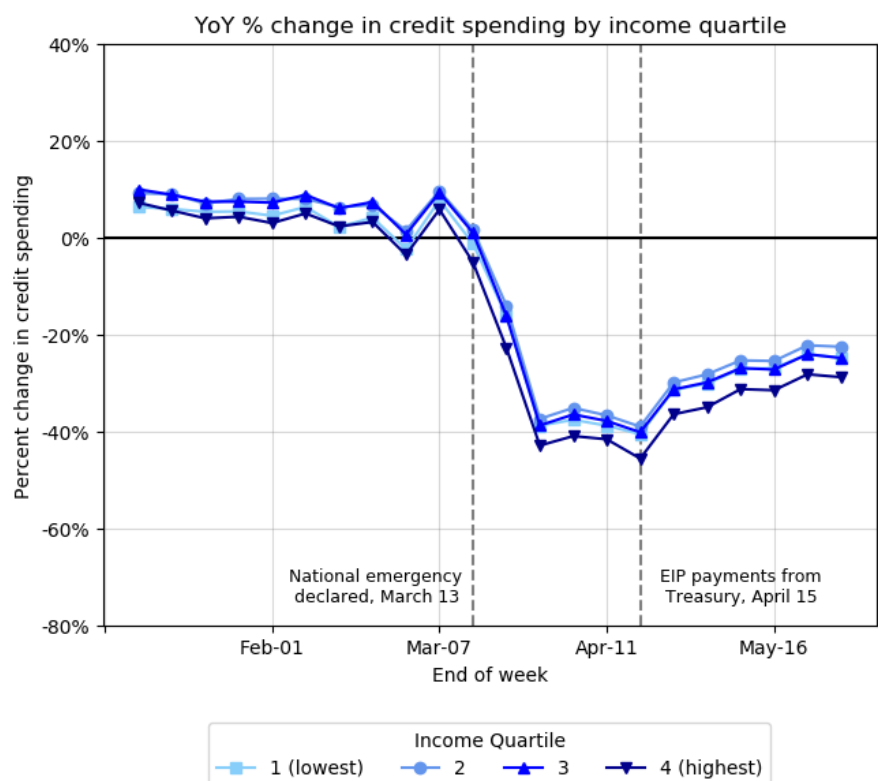

(b) Levels

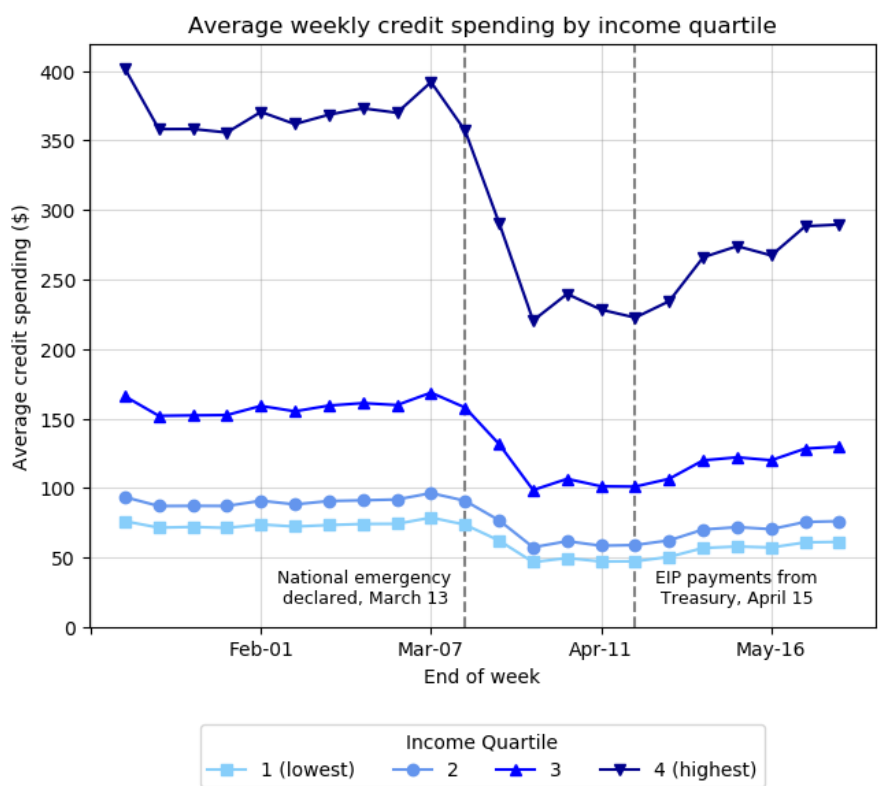

Figure A.7: Debit card spending by income quartiles

(a) Percent Change

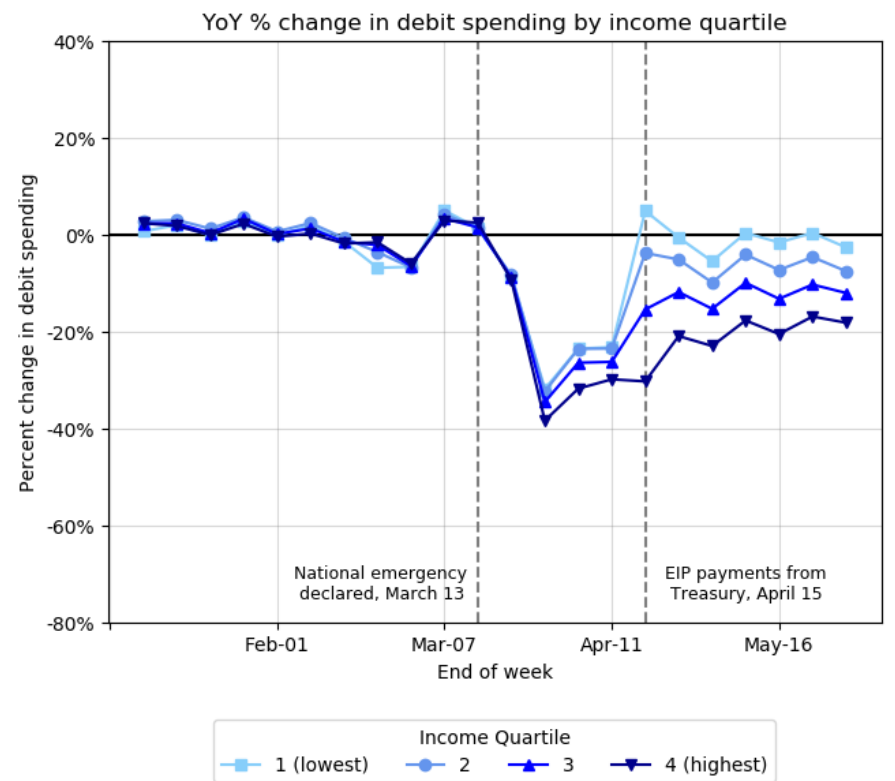

(b) Levels

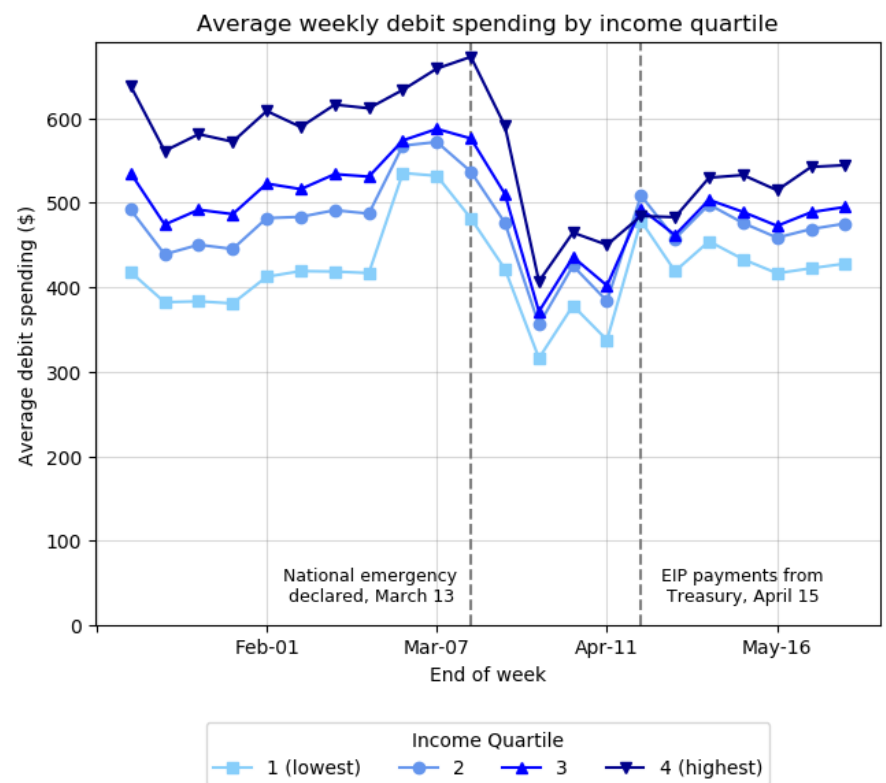


Figure A.8: Cash spending by income quartiles

(a) Percent Change

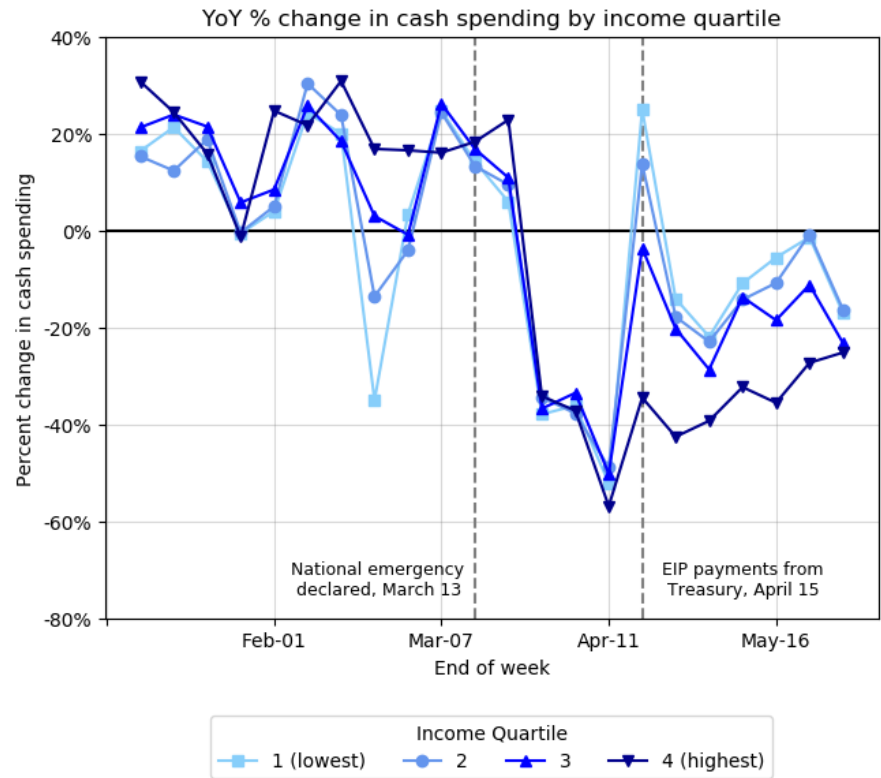

(b) Levels

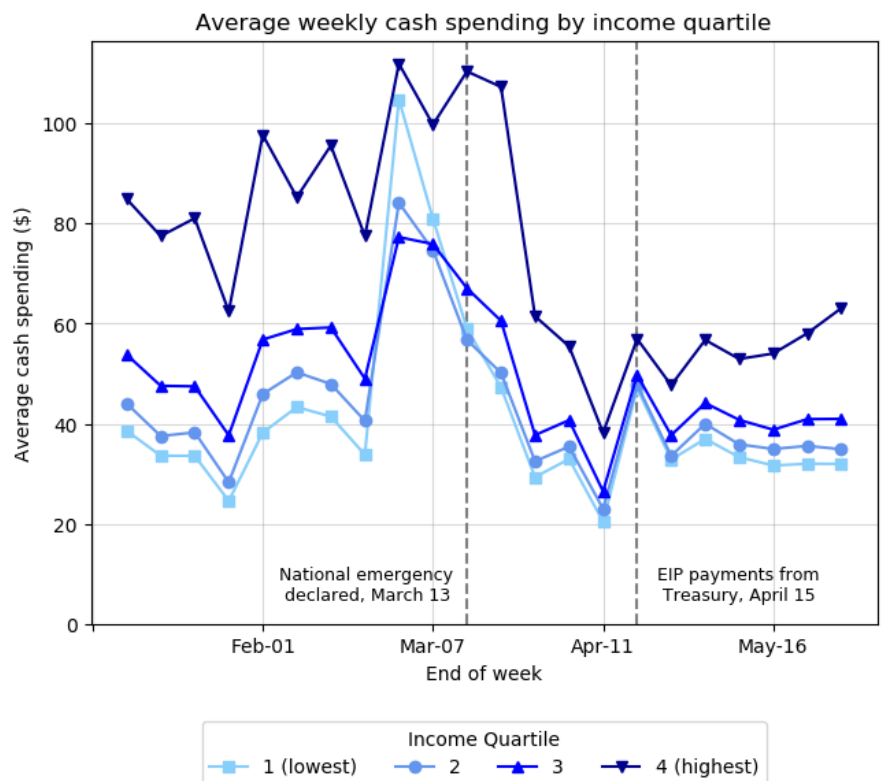

Cash withdrawals at ATMs using debit cards are reflected in the debit card series, so this series primarily reflects cash withdrawals with bank tellers.

Figure A.9: Check spending by income quartiles

(a) Percent Change

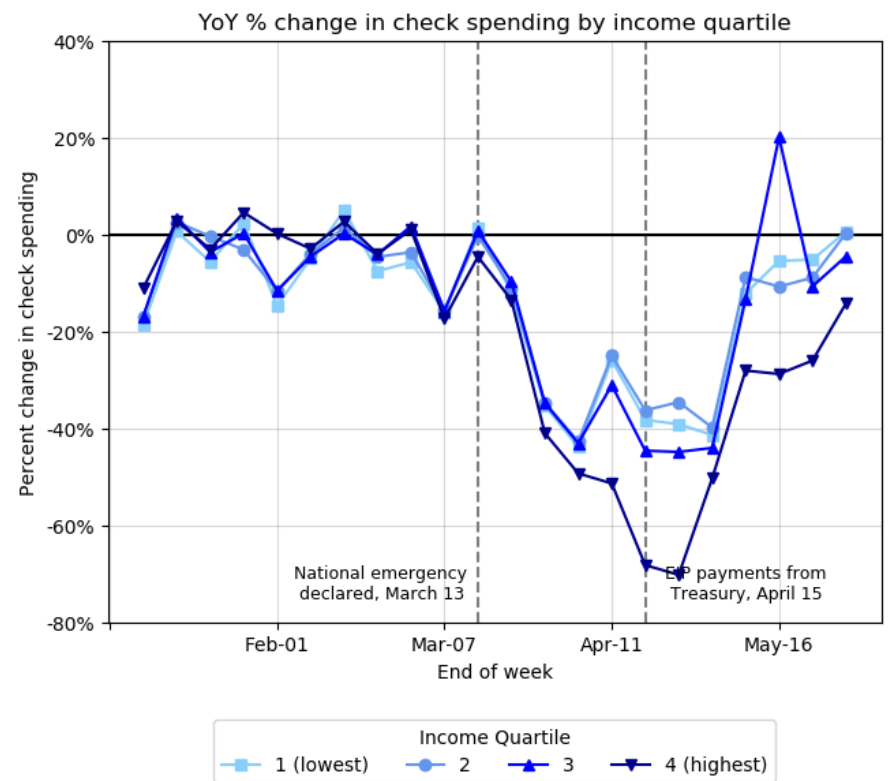

(b) Levels

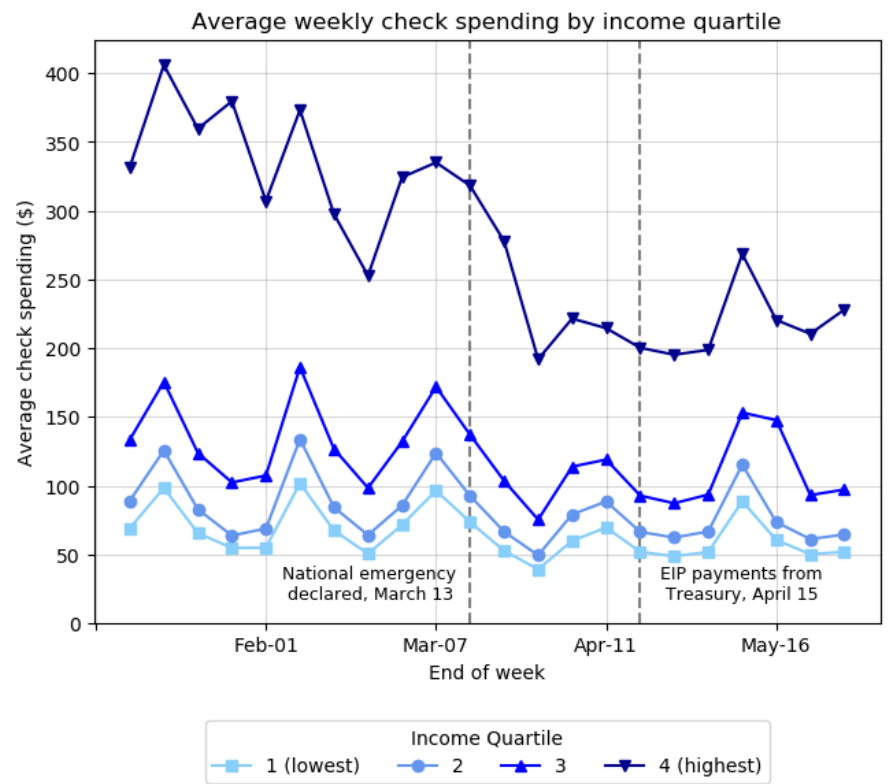


Figure A.10: Total spending by income quartiles (Inclusive of Checks)

(a) Percent Change

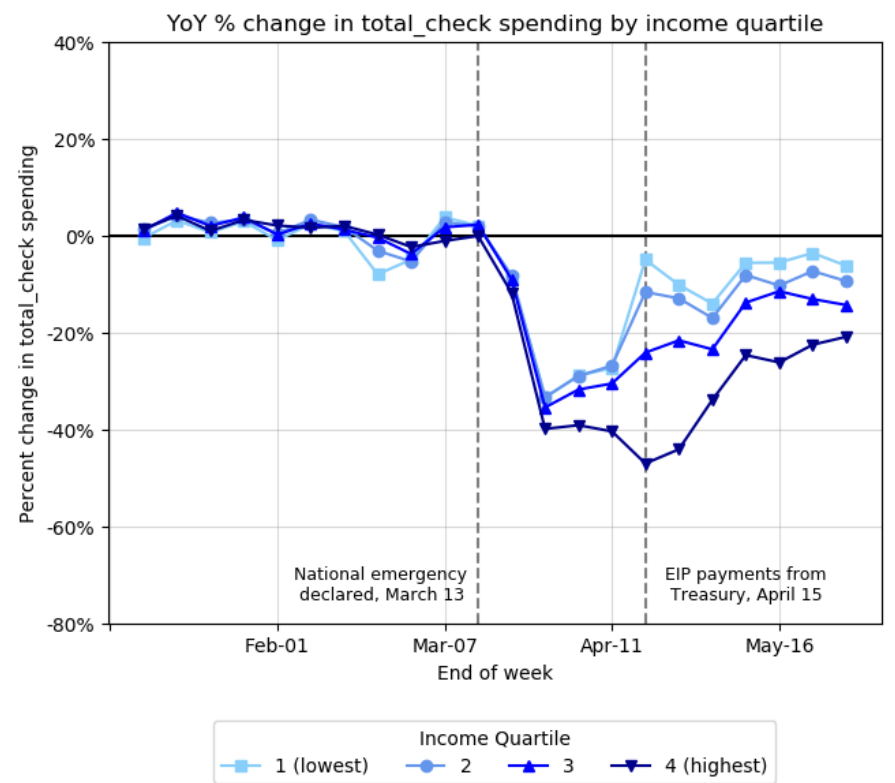

(b) Levels

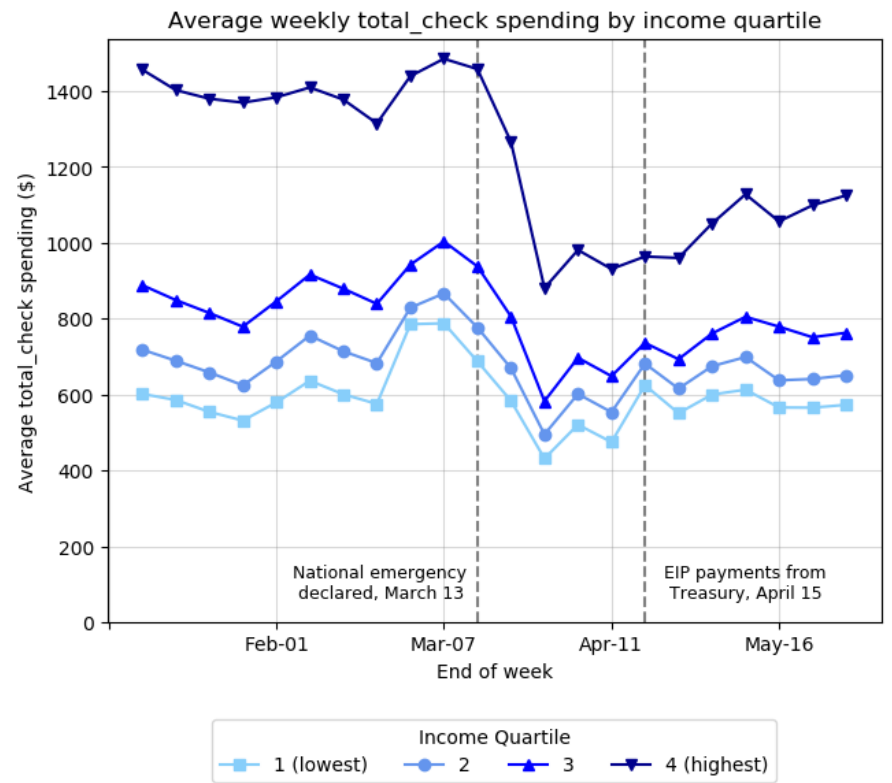

Table A.1: Decomposition of Total Spending Changes by Income Quartile

\begin{tabular}{|c|c|c|c|c|c|c|}
\hline & $\begin{array}{c}\text { Initial } \\
\text { Spending }\end{array}$ & $\begin{array}{c}\text { Share of } \\
\text { Initial } \\
\text { Spending }\end{array}$ & $\begin{array}{c}\text { Decrease in } \\
\text { Spending }\end{array}$ & $\begin{array}{c}\text { Share of } \\
\text { Decrease in } \\
\text { Spending }\end{array}$ & $\begin{array}{c}\text { Final } \\
\text { Spending }\end{array}$ & $\begin{array}{c}\text { Final } \\
\text { Spending }\end{array}$ \\
\hline Quartile 1 & \$7.66B & $17.8 \%$ & $-\$ 0.89 \mathrm{~B}$ & $10.2 \%$ & $\$ 6.78 \mathrm{~B}$ & $19.7 \%$ \\
\hline Quartile 2 & $\$ 8.93 \mathrm{~B}$ & $20.8 \%$ & $-\$ 1.30 \mathrm{~B}$ & $15.0 \%$ & $\$ 7.63 \mathrm{~B}$ & $22.2 \%$ \\
\hline Quartile 3 & $\$ 10.71 \mathrm{~B}$ & $24.9 \%$ & $-\$ 2.14 \mathrm{~B}$ & $24.6 \%$ & $\$ 8.57 \mathrm{~B}$ & $25.0 \%$ \\
\hline Quartile 4 & $\$ 15.73 \mathrm{~B}$ & $36.5 \%$ & $-\$ 4.37 \mathrm{~B}$ & $50.2 \%$ & $\$ 11.36 \mathrm{~B}$ & $33.1 \%$ \\
\hline Total & $\$ 43.04 \mathrm{~B}$ & $100.0 \%$ & $-\$ 8.70 \mathrm{~B}$ & $100.0 \%$ & $\$ 34.34 \mathrm{~B}$ & $100.0 \%$ \\
\hline & & & & & & \\
\hline Top Decile & \$7.58B & $17.6 \%$ & $-\$ 2394 \mathrm{M}$ & $27.5 \%$ & $\$ 5.19 \mathrm{~B}$ & $15.1 \%$ \\
\hline Top One Percent & \$1.04B & $2.4 \%$ & $-\$ 409 \mathrm{M}$ & $4.7 \%$ & $\$ 0.63 \mathrm{~B}$ & $1.8 \%$ \\
\hline
\end{tabular}

Initial spending is computed as total spending in 2019 for the 11 weeks between March 15 and May 30. Final spending is computed as total spending over the same 11 "pandemic" weeks in 2020. 


\section{A.3 Spending by Industry of Employment}

Figure A.11: Spending Changes Split by Industry of Employment

(a) Spend by Income Quartile 1

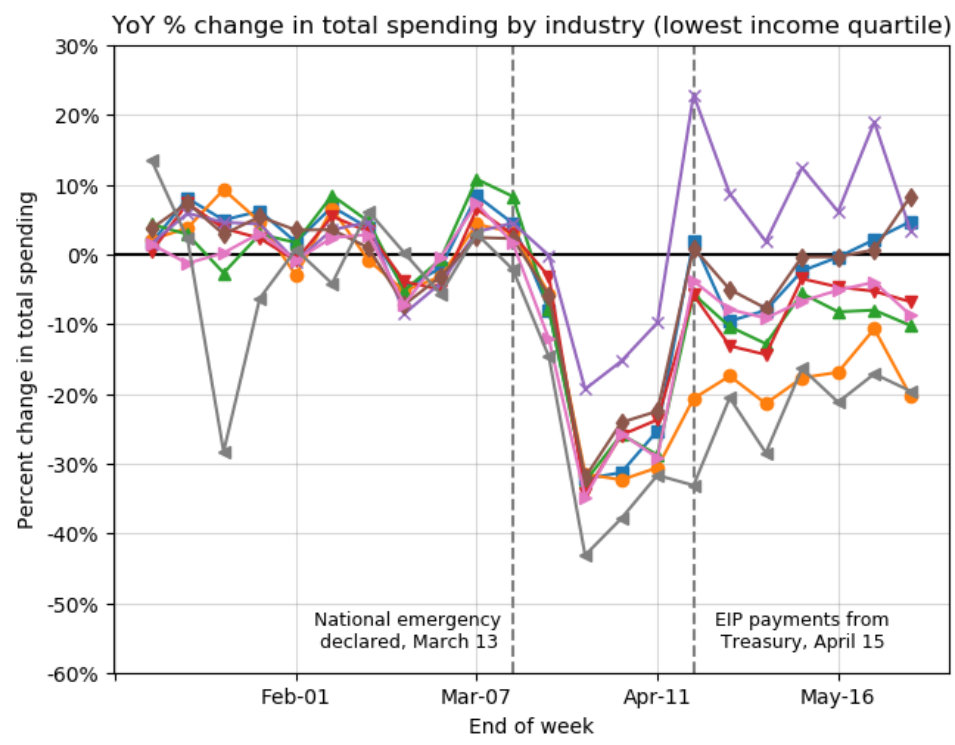

Industry of Employment

- Clothing and Department stores $\quad *$ Grocery, Drugstore, Discount stores $\longrightarrow$ Education

$\rightarrow$ Government $\rightarrow$ Manufacturing

$\longleftarrow$ Professional (b) Spend by Income Quartile 4

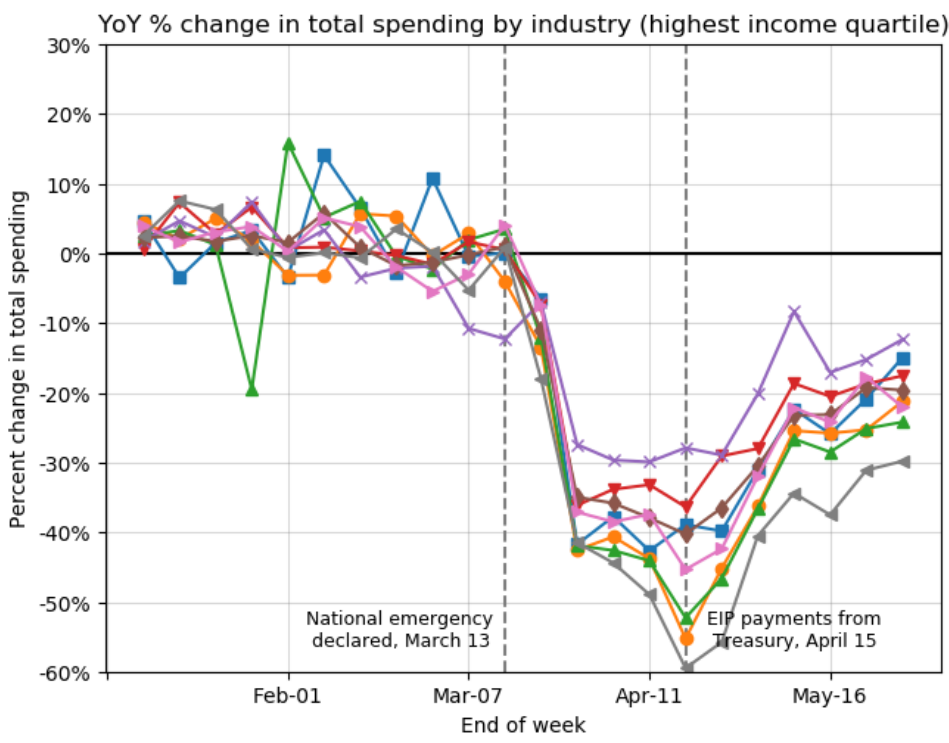

Industry of Employment

- Clothing and Department stores $\quad *$ Grocery, Drugstore, Discount stores $\rightarrow$ Education

$\rightarrow$ Government $\rightarrow$ Manufacturing

$\longleftarrow$ Professional

\section{A.4 CPS and Chase Sample Income Comparison}


Figure A.12: Comparison of income quartiles for Chase sample and CPS population

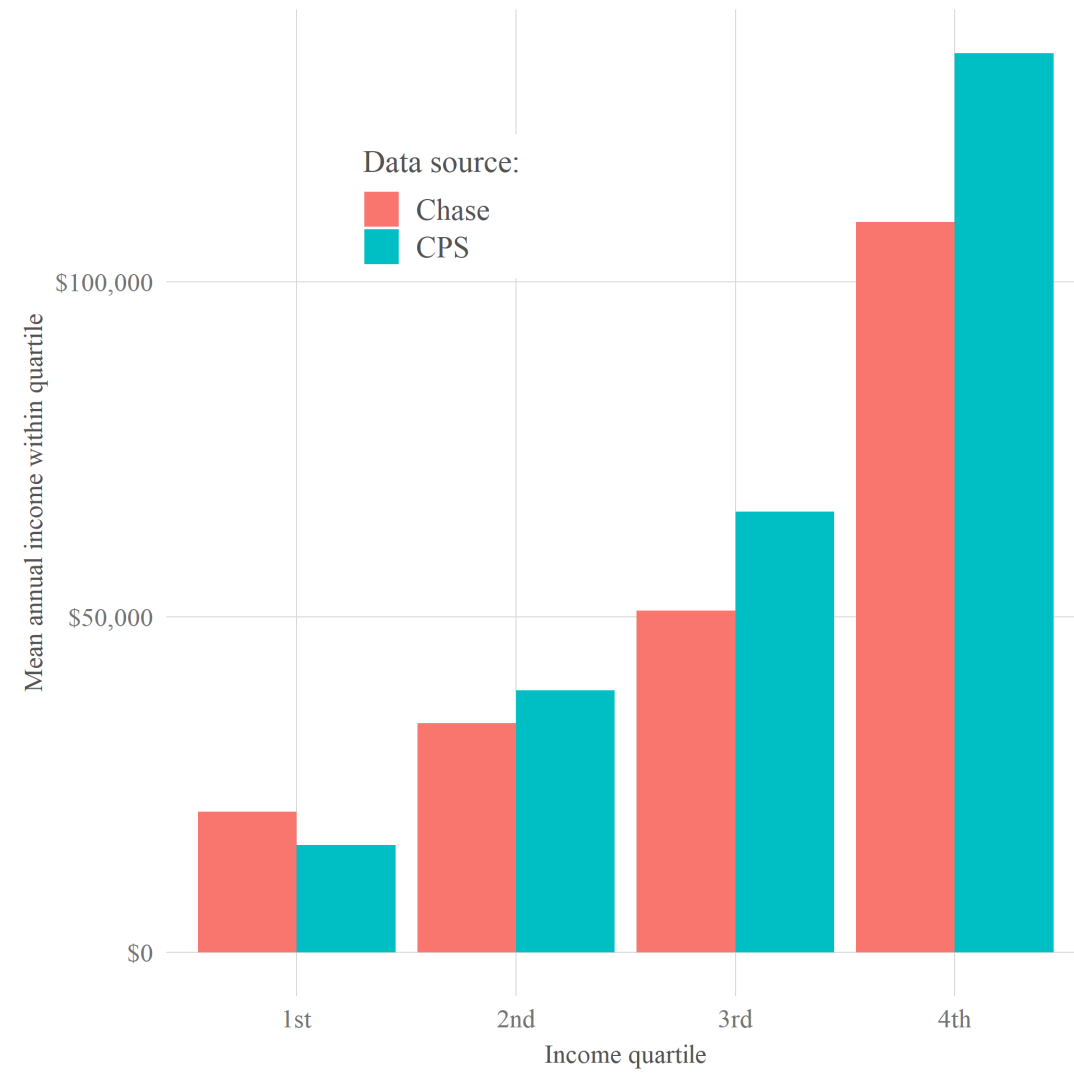

This figure compares average labor income by quartile in our analysis sample to those in the CPS. Since we only observe post-tax income in the Chase sample, we adjust the CPS income measure downwards to account for income and payroll taxes.

Table A.2: Average Income by Industry of Employment

\begin{tabular}{|c|c|c|}
\hline Industry & Total Monthly Pay & Average Monthly Pay \\
\hline Clothing/Dept Store & $\$ 76,279,559$ & $\$ 2,266$ \\
Grocery/Drug/Discount Store & $\$ 309,150,823$ & $\$ 3,932$ \\
Education & $\$ 169,907,642$ & $\$ 3,918$ \\
Government & $\$ 1,215,885,445$ & $\$ 3,762$ \\
Health Care & $\$ 114,163,903$ & $\$ 5,704$ \\
Manufacturing & $\$ 651,859,889$ & $\$ 5,772$ \\
Finance & $\$ 344,412,048$ & $\$ 5,423$ \\
Professional & $\$ 251,134,078$ & $\$ 2,366$ \\
\hline
\end{tabular}

This table lists the average monthly income for individuals in the debit card sample (column 2) and credit card sample (column 3) that are employed in each industry. 


\section{A.5 Additional Results}

\section{Figure A.13: Year-over-year growth in aggregate bank deposits}

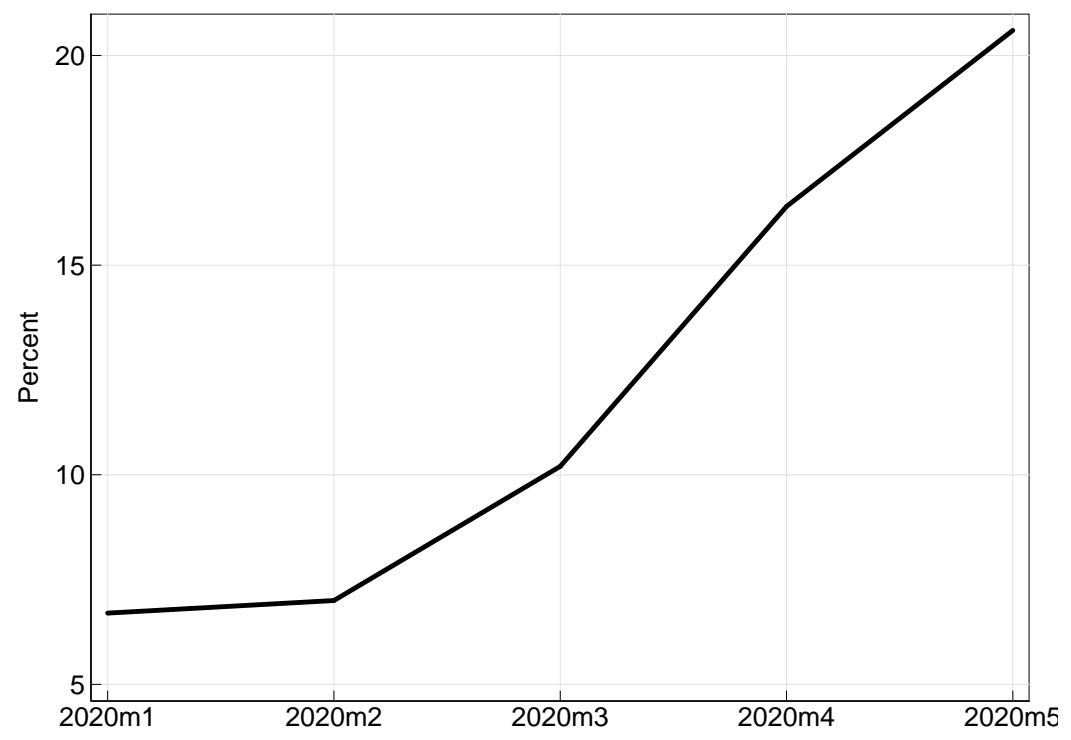

This figure plots aggregate year over year growth in all commercial bank deposits, using data from the Fed Board of Governors Release H.8

\section{A.6 Simulation of distribution of income changes}

We simulate the changes in income for households using the March 2019 Current Population Survey Annual Social and Economic Supplement (CPS ASEC). We require average hourly earnings of at least the federal minimum wage and to avoid issues with eligibility for transfers we also require that earners are citizens. We cut the sample into weekly earnings quintiles and allow the unemployment rates to vary between quintiles and month. We calculate a separate unemployment rate for each quintile and year using the CPS merged to the Earner Study in the CPS. We merge to the earner study taken at least 8 month prior to the observation period where we measure unemployment. For 2019, we take the unemployment rates pooling across April, August and December. For 2019, we match to the April CPS only. To produce variation by month, we re-scale these unemployment rates so as to match the national unemployment rate in aggregate in each month, including among the unemployed those who were misclassified as absent from work for other reasons. We randomly assign individuals in the ASEC to unemployment at the rates described above.

If an unemployed worker receives unemployment benefits, we calculate their regular Unemployment Compensation (UC) according to the calculator used in Ganong, Noel, and Vavra (2020). In our simulation, a worker cannot receive regular UC if they have insufficient earnings history 
according to the rules of their state. Additionally we calculate a recipiency rate among monetarily eligibles, using the ratio of actual benefits paid out in DOL ETA Form 5159 to the implied value of benefits if every eligible person in our simulation was receiving benefits. For example in April 2020, we calculate that $55 \%$ of eligible benefits were paid out and assume that $55 \%$ of eligibles receive benefits. In 2020, we include the possibility of additional unemployment benefits from the CARES Act: both the $\$ 600$ weekly supplement (Federal Pandemic Unemployment Compensation) and the insurance for those with insufficient wage earnings to qualify for regular UC (Pandemic Unemployment Assistance). For both of these policies we use data on the rollout of these policies from the Hamilton Project (Nunn, Parsons, and Shambaugh 2020). An unemployed worker receives an additional $\$ 600$ in their UC at random, with the probability corresponding to the share of workers who live in a state that had rolled out FPUC at that time. An unemployed worker who is monetarily ineligible for benefits receives a total compensation of $\$ 600$ at random, with the probability corresponding to the share of workers who live in a state that had rolled out FPUC at that time and adjusting for the recipiency rate described above.

We additionally model Economic Impact Payments (EIPs) assuming that Adjusted Gross Income (which is used to determine EIP eligibility) is equal to household income in the CPS. We allow each CPS household at most one EIP, which is $\$ 1200$ plus $\$ 500$ per child in the household. We allow a household an economic impact payment if they have an income which is sufficiently low to receive the full payment: we do not model the phase out, instead we give a household no EIP if they would have received a reduced payment.

To calculate changes, we find the percentage change in expected income for each household with and without the transfers. We then average the expected changes over households within the income quartiles. The income quartile cutoffs are taken from the Chase sample (so exclude anyone with income below 12,000), and are calculated on household labor income, which we adjust for tax. 